\title{
Determination of path attenuation and site characteristics of the North-west Himalayan region and adjoining regions within the Indian Territory using Generalized inversion method
}

\author{
Nelliparanbil Hareeshkumar Harinarayan ${ }^{1}$ and Abhishek Kumar*,2 \\ (1) Research Scholar, Department of Civil Engineering, Indian Institute of Technology Guwahati, Assam, India. \\ ${ }^{(2)}$ Assistant Professor, Department of Civil Engineering, Indian Institute of Technology Guwahati, Assam, India
}

Article history: received May 22, 2019; accepted May 5, 2020

\begin{abstract}
North-west Himalayas and its adjoining regions have been experiencing deadly earthqaukes from time to time and are home for a large portion of population of Indian subcontinent. Knowledge of regional path attenuation and site parameters are prerequisite while attempting seismic hazard studies towards minimizing damages during future earthqaukes for a region. Present work focuses on the determination of path attenuation and site characteristics of earthqaukes recording stations, located in the north-west Himalayas and its adjoining regions, within India. It is done using twostep generalized inversion technique. In the first step of inversion, non-parametric attenuation curves are developed by constraining attenuation to be a smooth decaying function with hypocentral distance. $\mathrm{Q}_{\mathrm{S}}=(105 \pm 11) \mathrm{f}^{(0.94 \pm 0.08)}$ as $\mathrm{S}$ wave quality factor is obtained indicating that the region is seismically active having high degree of heterogeneities in the crustal medium. In the second step of generalized inversion, site amplification curve, at each recording station, is computed as the ratio of site spectral amplitude of horizontal and vertical components. In addition, based on Horizontal to vertical spectral ratio (HVSR) method, predominant frequency of each recording station is calculated. Values of predominant frequencies based on HVSR and generalized inversion are found matching for each of the recording station. Based on obtained predominant frequency, site class of 101 recording stations, which at present are absent, are determined in this work. Determined path attenuation as well as site parameters can be collectively used for developing regional ground motion models and subsequently for seismic hazard studies for the selected region.
\end{abstract}

Keywords: Earthquake; Path attenuation characteristics; Quality factor; site characteristic; Generalized Inversion; HVSR.

\section{Introduction}

The Himalayan arc, extending approximately 2500km between Kashmir and Arunachal Pradesh within India, is one amongst the most seismically active regions across the globe. High level of seismic activity of this region can be understood based on induced damages witnessed primarily during 4 great earthquakes (EQs) including 1897 Shillong 


\section{Nelliparanbil Hareeshkumar Harinarayan and Abhishek Kumar}

EQ, 1905 Kangra EQ, 1934 Bihar-Nepal EQ and 1950 Assam EQ, which occurred in the last 120 years. Based on seismotectonic characterization, the entire Himalayan belt was subdivided into three distinct segments namely; the North-western, the Central and the Eastern Himalayas [Bungum et al., 2017]. The Himalayan region and its foothills, within India come under seismic zone IV and V as per IS 1893: [2016], indicating regions of high to very high seismicity. Therefore, the necessity of precise seismic hazard assessment of this region is of great importance.

Intensity of ground shaking during an EQ, at a particular site is a collective effect of source, path and site parameters. Source parameters include magnitude, fault mechanism, stress drop and rupture process. On the other hand, path parameters account for the reduction in the energy of seismic waves (called attenuation of seismic waves) during its propagation in the medium. Attenuation of seismic waves is caused due to scattering of elastic waves in the heterogeneous medium and anelasticity of the earth medium, and is measured in terms of a dimensionless parameter known as quality factor (Lay and Wallace, 1995). Another important parameter which influences the nature of ground motion during an EQ is the site parameter. It accounts for the modification in amplitude, frequency content and duration of the incoming seismic wave by subsurface medium. The determination of aforementioned EQ parameters at regional level is important for the development of region specific synthetic ground motion models, which can further be used for region/site specific seismic hazard assessment [Baro et al., 2018]. Above EQ parameters are estimated in this work from regional ground motion records using an inversion approach based on generalized inversion method [e.g. Andrews, 1986; Castro et al., 1990; Oth et al., 2009].

In order to understand the ongoing seismicity of various regions within India, the Government of India had installed a number of EQ recording stations in different parts of the country. All these recording stations and corresponding ground motion records, since 2004, are handled by PESMOS (Program for Excellence in Strong Motion Studies). At present, PESMOS manages EQ records from 300 recording stations which are distributed in the northern and northeastern parts of India as well as in the Andaman and Nicobar Islands [Kumar et al., 2012]. Thus, PESMOS is considered as the most significant resource of ground motion records in India. Along with ground motion data, PESMOS provides information regarding magnitude and localization of EQs. However, it must be highlighted here that PESMOS database is lacking in terms of accurate information about subsurface for majority of recording stations [Kumar et al., 2012; Harinarayan and Kumar, 2018]. Site class (SC) given by PESMOS is based on physical description of surface materials and local geology following Seismotectonic Atlas of India (GIS 2000) and Geological Maps of Indian [GSI, 1998] and hence not based on actual field investigation (Kumar et al. 2012). In the absence of accurate information about local soil, utilizing EQ records from PESMOS database for region specific seismic studies is a major challenge. Subsurface exploration studies on some of the recording stations in north-west Himalayas by Pandey et al. [2016a; b] had highlighted the above limitation in SC given by PESMOS. There are recording stations which are classified to be located on rock site as per PESMOS but were found to be located on soil sites by Pandey et al. [2016a; b]. In another work, Harinarayan and Kumar [2018] attempted site classification of 90 recording stations of PESMOS located in the northwest Himalayas and reported mismatch with respect to SC given by PESMOS.

In the present study, EQ records from PESMOS recording stations located in the north-west Himalayas and its foothills within India (including the states of Himachal Pradesh, Uttarakhand, Punjab, Haryana and New Delhi), are analysed for estimating path attenuation and site characteristics separately. It is done based on two-step generalized inversion (GINV) of the S-wave Fourier spectra (hereafter referred to as GINV). In the first step, attenuation curves are developed using a non-parametric inversion approach [Castro et al., 1990; Oth et al., 2008] considering 207 ground motion records from 69 recording stations. In the conventional generalized inversion method [Andrews, 1986; Hartzell, 1992], the second step of inversion calculates both site and source spectra, by inverting the S-wave (or Coda wave) spectra, corrected for the path parameter. This method, however, requires one or more reference sites (usually rock sites) in-order to remove the trade-off between the source and the site parameters [Andrews, 1986]. In the absence of subsoil information for a majority of recording stations managed by PESMOS as highlighted above, identifying reference site is not possible. For this reason, the site parameters are evaluated in the second step of inversion using a non-reference generalized inversion approach [Joshi et al., 2010; Harinarayan and Kumar, 2017b] based on 341 ground motion records from 86 EQs recorded at 101 recording stations. Further, obtained site terms are compared with the one calculated from horizontal to vertical spectral ratios (HVSR), based on the same S-wave window as used earlier in GINV analysis.

This study is one of its kinds, which systematically evaluates path attenuation and site parameters using a larger set of regional grounds motion records. Available studies on attenuation characteristics of north-western Himalayas are in fact based on few EQ records from limited recording stations. Sharma et al. [2015] determined the frequency 
independent $\mathrm{S}$-wave quality factor $\left(\mathrm{Q}_{S}\right)$ for Delhi region using the coda normalization method based on ground motion records from 9 recording stations. In another study, Negi et al. [2015] estimated $\mathrm{Q}_{s}$ for the Garhwal Himalayas (western part of Uttarakhand) using extended coda normalization method based on 40 ground motion records from 8 recording stations. Using a similar method as done by Negi et al. [2015], Singh et al. [2012] estimated $\mathrm{Q}_{S}$ for the Kumaun Himalayas (eastern part of Uttarakhand) based on ground motions from $23 \mathrm{EQ}$ events from 9 recording stations. In another study, Mukhopadhyay et al. (2014) estimated $Q_{s}$ for the Uttarakhand region using Multiple Lapse Time Window Analysis (MLTWA) method considering ground motions from $30 \mathrm{EQ}$ events from 5 recording stations. Results of the aforementioned studies will be discussed in conjunction with those from the present study.

Similar to path attenuation studies, very few studies on the determination of site characteristics from EQ records exist for this region. Nath et al. [2002] computed site terms using the aftershocks of the 1999 Chamoli EQ, obtained from 5 recording stations located in the Uttarakhand region. Similarly, Sharma et al. [2014] estimated site parameters for the Garhwal region of Uttarakhand using EQ records in context with generalized inversion and HVSR. In another work, Harinarayan and Kumar [2017] reported a comparative study on site characteristics that were computed using EQ records from Tarai region of Uttarakhand using multiple analytical approaches. Similarly, Harinarayan and Kumar [2018] computed site parameters for recording stations in the north-west Himalayas in terms of predominant frequency $\left(f_{\text {peak }}\right)$ alone using Horizontal to vertical spectral ratio (HVSR) based on the response spectra of the entire accelerogram.

\section{Study area}

Present study area includes the states of Himachal Pradesh, Uttarakhand, Punjab, Haryana and New Delhi. It covers an area between $28^{\circ} \mathrm{N}$ to $34^{\circ} \mathrm{N}$ latitude and $75.8^{\circ} \mathrm{E}$ to $80.5^{\circ} \mathrm{E}$ longitude. According to 2011 Census, this region has a population of 96 million. From seismicity point of view, major seismotectonic features of the study area consist of three north-dipping thrust systems such as the Main Central thrust (MCT), the Main Boundary thrust (MBT) and the Himalayan frontal thrust (HFT) [Valdiya, 1981]. The MCT and the MBT run parallel to each other within north-western Himalayan region and were produced during the Cenozonic shortening [Malik and Nakata, 2003]. The HFT is the youngest active thrust separating the Himalayan region and the Indo-Gangetic alluvial plain [Kumar et al., 2009]. The HFT, the MBT and the MCT so far have generated numerous major EQs in this region [Philip et al., 2014]. Other tectonic features include the Jhelum Balakot fault, the Drang thrust, the Lesser Himalayan Crystalline Nappes, the Jammu thrust, the Vaikrita thrust, the Karakoram fault, the Jwala Mukhi thrust, and the Ramgarh thrust. As a result of the presence of above mentioned seismic sources, the region has been experiencing repeated EQs. Two most damage inducing EQs in the region in the last 120 years include 1905 Kangra-Himachal Pradesh EQ (Ms=7.8) [Ambraseys and Douglas, 2004] and 2005 Muzzafarbad-Kashmir EQ (Mw=7.6) [Avouac et al., 2006]. Both of these EQs had caused large number of casualties as well as damage to property. 1905 Kangra EQ killed more than 20,000 people and caused $15 \mathrm{~cm}$ uplift in Dehradun region located $250 \mathrm{~km}$ from the epicentre [Ambraseys and Bilham, 2000]. The 2005 Muzzafarbad-Kashmir EQ claimed more than 80,000 lives and caused extensive damages to buildings in Jammu and Kashmir regions [Kamp et al., 2008]. The 2005 Muzzafarbad-Kashmir EQ also triggered several landslides along the Jhelum and Neelum valleys in Kashmir region [Kamp et al., 2008]. Recent moderate EQs of 1991 Uttarkashi (Mw=6.8) and 1999 Chamoli $(\mathrm{Mw}=6.6)$ had occurred on the MCT [Harbindu et al., 2014]. The 1991 Uttarkashi EQ damaged 100,000 houses claiming 769 lives and triggered several landslides in the Uttarkashi region [Kayal, 1996]. The 1999 Chamoli EQ caused a huge landslide in Gopeshwar situated less than 2km north-west of Chamoli city [Sarkar et al., 2001]. This EQ also caused shaking in Chandigarh and Delhi, located far away from the epicentre [Mundepi et al., 2010]. Based on the discussion, a clear understanding about the seismic status of the region and damaging characteristics of a seismic event can be developed. Findings from present work will be very helpful in arriving at accurate seismic hazard values towards minimizing future $\mathrm{EQ}$ induced damages.

\section{Database}

Ground motion records used in this study consist of three components accelerograms obtained from PESMOS database (http://www.pesmos.com/). The instruments used for recording EQs consist of internal AC-63 GeoSIG triaxial force balanced accelerometers and GSR-18 GeoSIG 18 bit digitizers with external GPS [Kumar et al., 2012]. 


\section{Nelliparanbil Hareeshkumar Harinarayan and Abhishek Kumar}

Further, ground motion recordings are done in trigger mode during each EQ with a sampling rate of 200 per second. For the present analysis, ground motion records of EQs happened between 2004 and 2017 in the earlier discussed region, as available on PESMOS are used. For estimating site characteristics, 341 ground motion records from $86 \mathrm{EQs}$, with magnitudes ranging from $\mathrm{Mw}=2.3$ to 5.8 and having focal depths ranging from 2 to $80 \mathrm{~km}$ are used. Further, these ground motion records were recorded at 101 recording stations, located in the hypocentral distance range of 9 to $355 \mathrm{~km}$. Coordinates of each of the recording stations, used in this work are listed in Table 1. Further, details of EQs used for estimating site characteristics are summarized in Table 2.

For estimating path attenuation however, only those EQs which are recorded in at least two recording stations within which at least one recording station is located within hypocentral distance equal to or less than a reference distance (section 4.2 for further details) are considered in the analysis. Thus, out of 341 ground motion records which are used for estimating site parameters as mentioned earlier, only 207 ground motion records satisfy the above mentioned reference distance criteria are used in determining path attenuation. Thus, the database for estimating path attenuation consists of 207 ground motion records from $32 \mathrm{EQs}$ having magnitude in the range of 3.1 to $5.5(\mathrm{Mw})$, with focal depths in the range of 3 to $55 \mathrm{~km}$ and hypocentral distance in the range of 9 to $200 \mathrm{~km}$, recorded at 69 recording stations. Table 3 summarizes the details of the dataset used for estimating path attenuation. In addition, Figure 1 shows source-to-recording station path of the dataset used in the present study for estimating path attenuation.

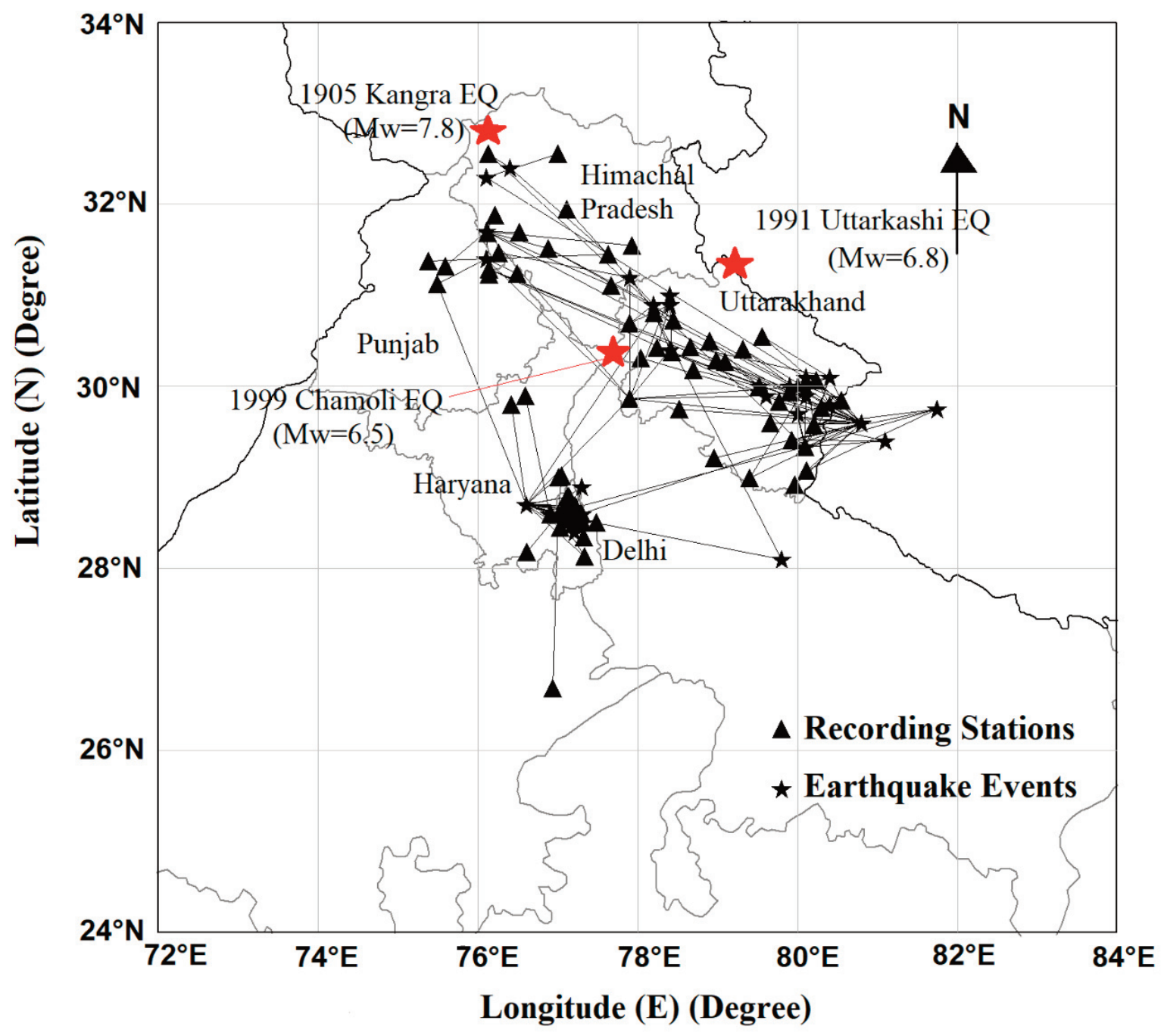

Figure 1. Map of the region under study with EQs (stars), recording stations (triangles), and paths (solid-lines). 


\subsection{Data processing}

Before a ground motion record is used for path attenuation or site characteristics determination, it is processed. All the EQ records are corrected by removing the baseline by a $5 \%$ cosine taper and a band-pass filtering using a Butterworth filter, between frequency range of $0.25 \mathrm{~Hz}$ and $15 \mathrm{~Hz}$. Later, S-wave portion of the accelerogram is separated. The beginning of S-wave arrival is manually picked based on visual inspection. Time window duration of $\mathrm{S}$-wave portion of the accelerogram is determined starting from $0.5 \mathrm{~s}$ before the beginning of the S-wave and ending when $90 \%$ of the total seismic energy of the EQ record is reached [Bindi et al., 2009; Ameri et al., 2011]. Typical lengths of the S-wave time windows to be used for further analysis vary from 4 to $15 \mathrm{~s}$. For some of the records, where the S-wave window length obtained is longer than $15 \mathrm{~s}$, it is fixed to $15 \mathrm{~s}$ in order to minimize coda wave energy in the analysing time window (Oth et al. 2008). Later, from the extracted windows, the Fourier amplitude spectra is calculated for each EQ record which is smoothened by applying the Konno and Ohmachi [1999] algorithm, with the smoothing parameter (b) as 20. Further, signal to pre-event noise (all having equal window length) ratio (SNR) for all the ground motion records is computed (similar to Wang et al. 2019). Figure 2 shows the example of SNR calculated for two ground motion records. Ground motion records with SNR $\geq 5$ [Ameri et al., 2011] are only considered for further analysis. At the end of the signal processing the ground motion waveforms are then used for the determination of path and site parameters based on two separate inversion procedures as described in the later sections.

a)
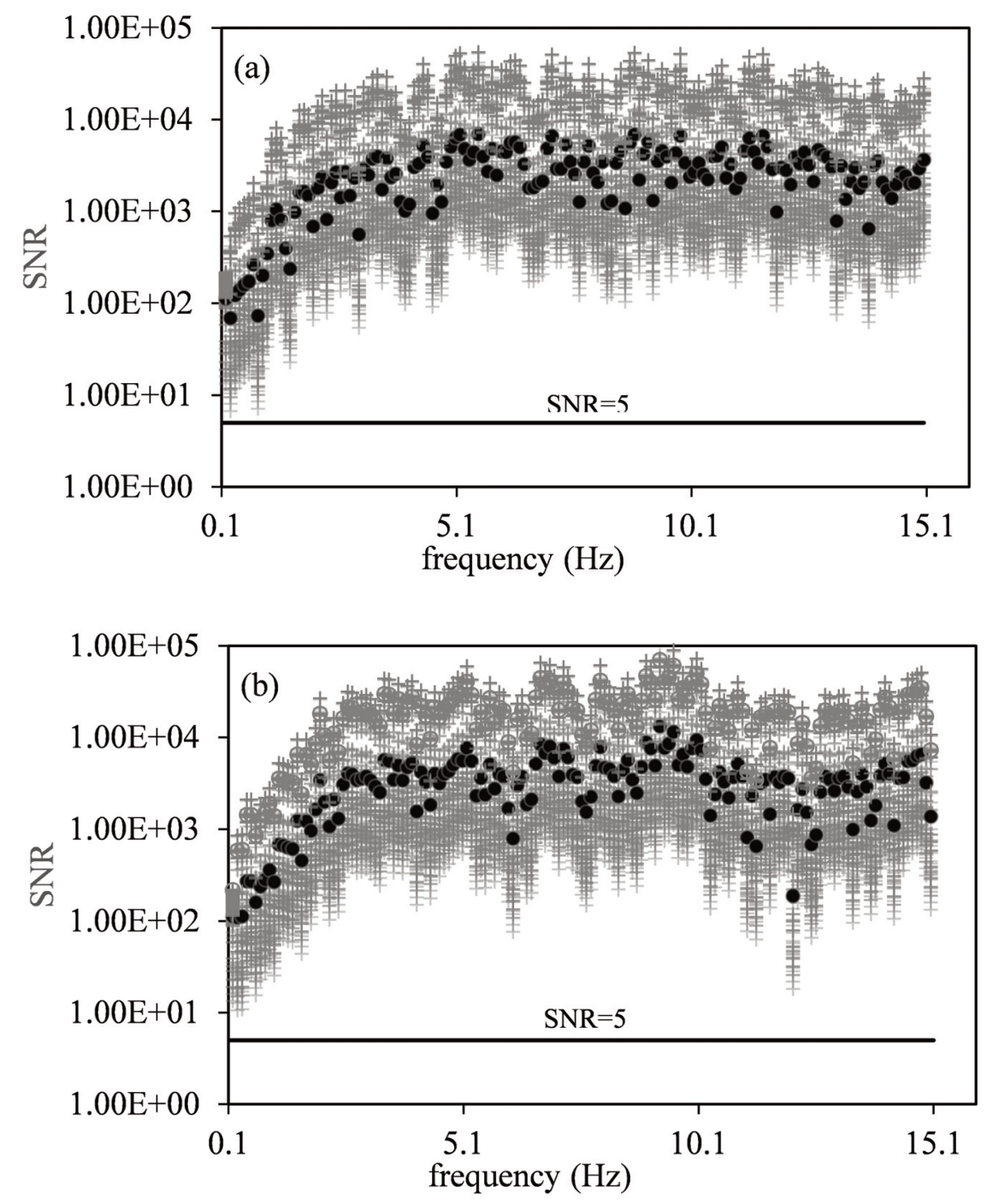

Figure 2. Signal to noise ratios (black crosses) vs frequency for typical two records (a: Recording station CHP-Event: 19/August/2008; b: Recording station PTH-Event: 19/September/2009). The median value of SNR for each frequency is indicated by black dots. 


\section{Nelliparanbil Hareeshkumar Harinarayan and Abhishek Kumar}

\section{Path attenuation}

In the first step of inversion, path attenuation curves (path attenuation in logarithmic scale versus hypocentral distance) are developed using a non-parametric approach where attenuation is constrained to decay smoothly with hypocentral distance. Detailed discussion can be found in following sub-sections.

\subsection{Methodology}

Following Castro et al. [1990], observed spectral amplitude $\left[\mathrm{U}_{\mathrm{ij}}\left(\mathrm{f}, \mathrm{R}_{\mathrm{ij}}\right)\right]$ of the horizontal portion of the accelerogram (obtained as the root mean square average of the east-west and north-south components), of $\mathrm{EQ}_{j}$ at recording station "i”, and at a particular frequency "f” can be modelled linearly as:

$$
\ln U_{i j}\left(f, R_{i j}\right)=\ln M_{j}(f)+\ln A\left(f, R_{i j}\right)
$$

Here, $M_{j}(f)$ is a scalar, which is governed by the magnitude of the EQ (one value for each EQ), $A\left(f, R_{i j}\right)$ is the attenuation function which is independent of the magnitude of the EQ. In Eq. (1), $A\left(f, R_{i j}\right)$ incorporates both geometric spreading and anelastic attenuation variation with hypocentral distance. Moreover, $A\left(f, R_{i j}\right)$ in Eq. (1) is not limited to a particular functional form, instead, is assumed to decay smoothly with hypocentral distance $\left(\mathrm{R}_{\mathrm{ij}}\right)$ and take the value $A\left(f, R_{0}\right)=1$ at a reference distance $\left(R_{0}\right)$ [Castro et al., 1990; 1996; 2003]. Representation given by Eq. (1) has no factor representing site effect separately, and thus site effect is contained in both and. Any rapid undulations in $\mathrm{A}\left(\mathrm{f}, \mathrm{R}_{\mathrm{ij}}\right)$ are assumed to be due to the absorbed site effects (Oth et al. 2008). Two weighing factors, $\mathrm{w}_{1}$ and $\mathrm{w}_{2}$ are incorporated in the Eq. (1) following Castro et al. [1990]. $\mathrm{w}_{1}$ is used to smoothen the path attenuation curve by supressing the undulations and thereby transferring any absorbed site effects in $A\left(f, R_{i j}\right)$ to $M_{j}(f)$. Further, $W_{2}$ is used to impose $A\left(f, R_{0}\right)=1$ constraint, as mentioned earlier. The value of $w_{1}$ is chosen such that the site effects in the term $A\left(f, R_{i j}\right)$ are supressed but the change in the attenuation characteristics with hypocentral distance can be clearly observed [Oth et al. 2008].

Eq. (1) can be expressed as a linear system of the form $A x=B$, where $B$ is the data vector having the term $\ln U_{i j}\left(f, R_{i j}\right)$, $x$ is the vector having model parameters $\left[\operatorname{lnM}_{j}(f)\right.$ and $\left.\ln A\left(f, R_{i j}\right)\right]$, and $A$ is the system matrix that relates $x$ and B. The matrix formulation of Eq. (1) after incorporating the weighting factors $\mathrm{w}_{1}$ and $\mathrm{w}_{2}$ (Castro et al. 1990) takes the form as follows:

(A)

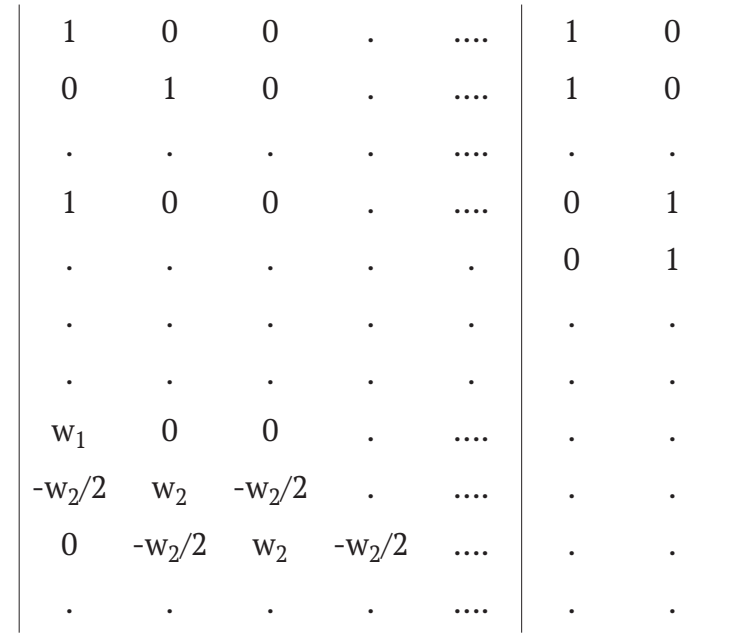

$(\mathrm{X})$

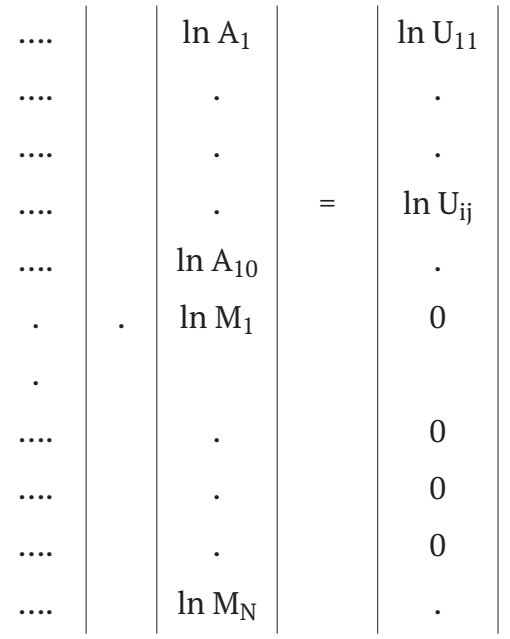

(b)
The hypocentral distances of the data set are discretized into number of bins of equal widths and the value of $\mathrm{A}\left(\mathrm{f}, \mathrm{R}_{\mathrm{ij}}\right)$ is computed for each bin. The width of the bins is selected such that there are sufficient numbers of data points 
in every bin. Figure 3 shows the number of $\mathrm{EQ}$ records in each bin of the present data set. It can be observed from Figure 3 that there are very less EQ records available beyond hypocentral distance of $115 \mathrm{~km}$. For this reason, EQ records with hypocentral distance up to $115 \mathrm{~km}$ are only considered for the determination of path attenuation curve. This hypocentral distance range from 15 to $115 \mathrm{~km}$ is divided into $11 \mathrm{bins}$ (10 km wide). Further, constraint $A\left(f, R_{0}\right)=1$ is applied at $R_{0}=15 \mathrm{~km}$ [Bindi et al. 2004], irrespective of the frequency. Further, path attenuation curves are computed separately for each frequency, solving Eq. (2) in a least square sense, using singular value decomposition method [Menke, 1989]. For each bin, path attenuation curves are computed at 18 frequencies ranging from $0.5 \mathrm{~Hz}$ to $15 \mathrm{~Hz}$ (see Table 4).

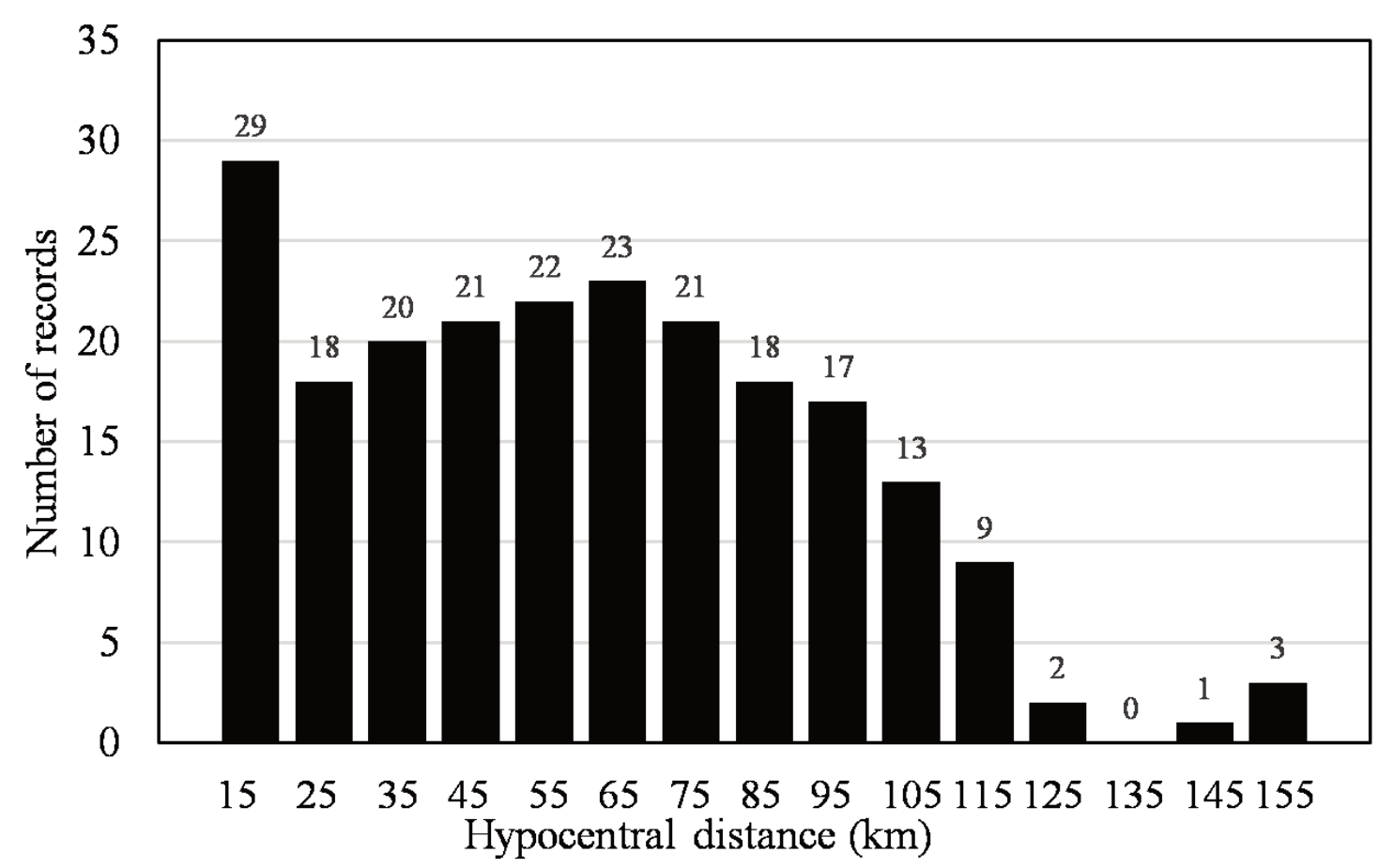

Figure 3. Distribution of hypocentral distances in the data set.

\subsection{Spectral attenuation with distance}

Variation of $\ln \mathrm{A}\left(\mathrm{f}, \mathrm{R}_{\mathrm{ij}}\right)$ with hypocentral distance, obtained from the above analysis, for selected frequencies is depicted in Figure 4. Based on Figure 4, a general trend in which path attenuation curves exhibit decay with hypocentral distance up an hinge distance of $105 \mathrm{~km}$ can be observed. The change in the attenuation rate in correspondence of the hinge distance can be clearly detected especially at lower frequencies $(<5.5 \mathrm{~Hz})$. The enhancement of the ground motion beyond $105 \mathrm{~km}$ might be do to the reflection of $\mathrm{S}$ waves at the Moho discontinuity [Oth et al., 2011; Saikia et al., 2016]. Bindi et al. [2004] and Oth et al. [2011] reported a similar trend in the attenuation curves for the Umbria Marche and Japan regions respectively. Oth et al. [2011] attributed that behaviour to the combined effect of reflected or refracted wave arrivals from Moho in Japan. For the north-west Himalaya, presence of the Moho, based on Teleseismic receiver function analysis, was reported by Saikia et al. [2016]. However, detailed study in this direction is required and is beyond the scope of the present work. After observing the attenuation curves at different frequencies as given in Figure 4, it can be concluded that for the present study region, higher frequency content $(>5.5 \mathrm{~Hz})$ of seismic wave, decays more rapidly between the source and the site in comparison to lower frequency content. This observation is consistent with the findings by Castro et al. [2003] for Guadeloupe (France) and Oth et al. [2011] for Japan. 


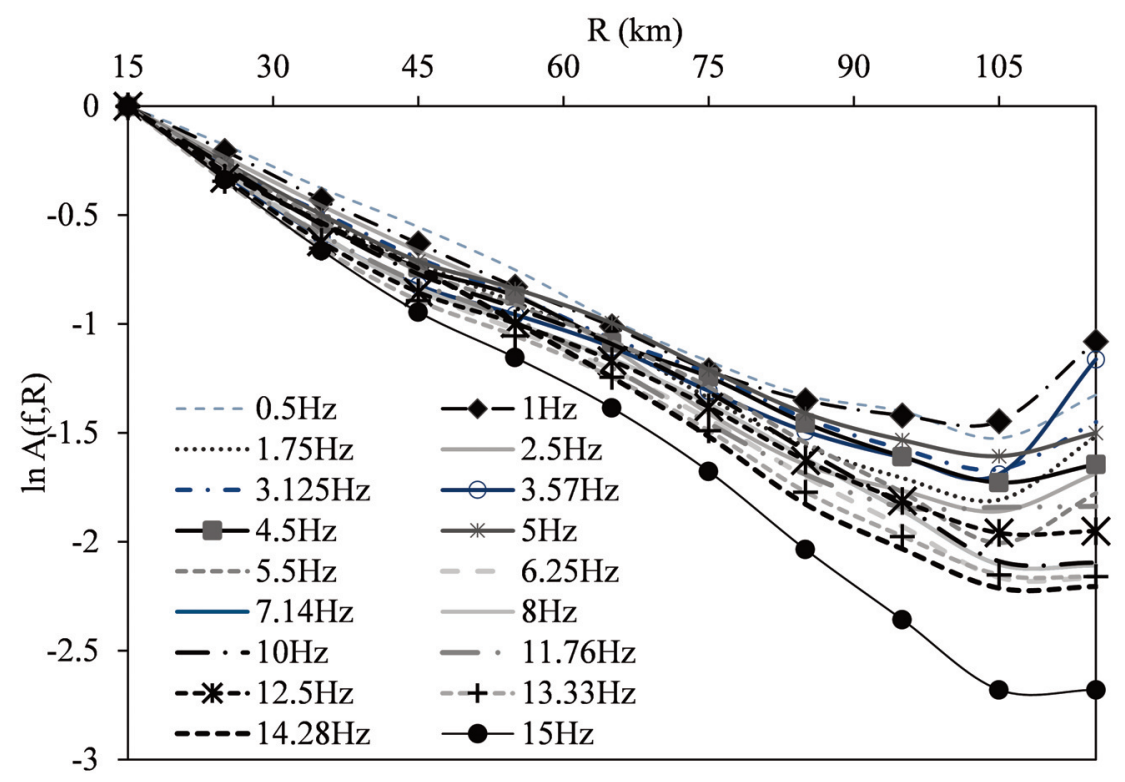

Figure 4. $\mathrm{S}$ wave spectral attenuation versus hypocentral distance. Note that $\ln \mathrm{A}\left(\mathrm{f}, \mathrm{R}_{0}\right)$ at reference distance is zero.

In order to assess the stability of the inverted path attenuation curves, bootstrap analysis [similar to Wang et al., 2018] is performed at each of the selected frequency points. 17 number of ground motion recordings (which accounts for approximately $8 \%$ of the total number of the ground motion records considered for analysis) are removed randomly from the data base, and the remaining ground motion records are considered as a new data set used for inversion. The above discussed procedure is repeated 100 times and inversion (discussed in section 4.1) is carried out for each of the 100 bootstrap samples. Figure 5 shows the inverted path attenuation curves obtained from 100 bootstrap analysis. It can be observed from Figure 5 that the deviation from the path attenuation curve obtained considering the entire data set is significantly small, indicating that the path attenuation curves obtained from inversion are stable.
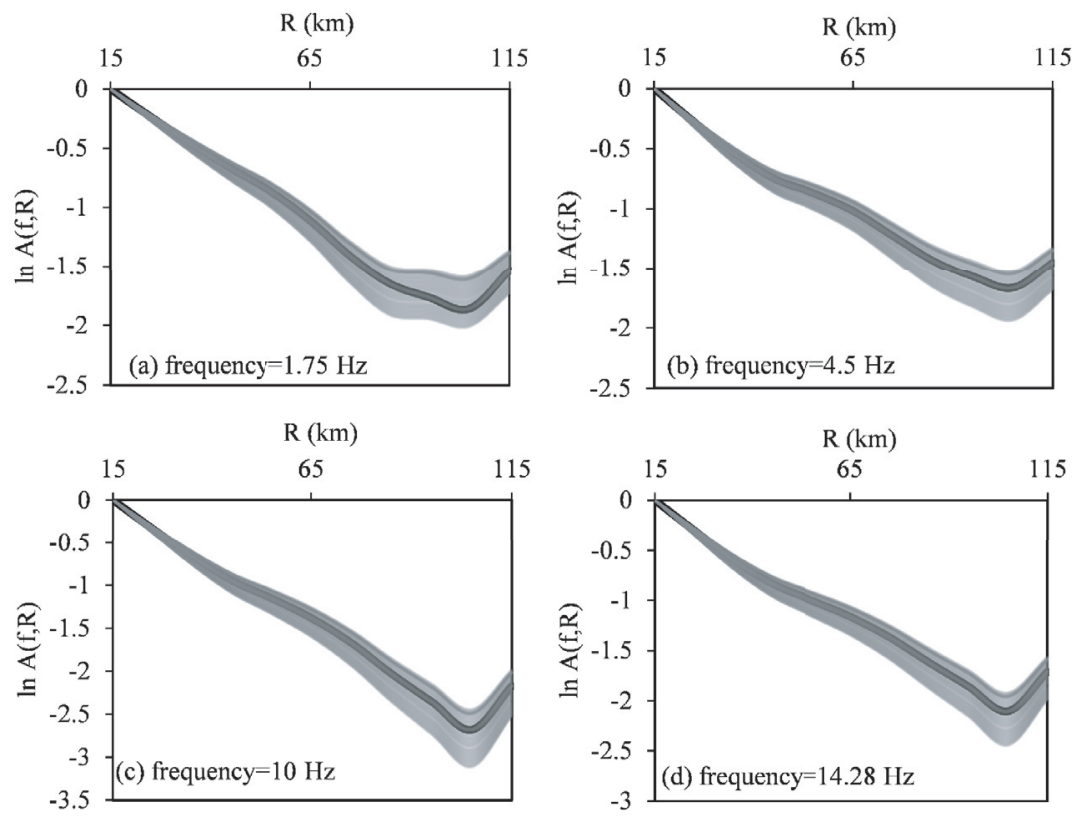

Figure 5. S wave spectral attenuation versus hypocentre distance for 4 typical frequencies. The dark line shows the attenuation curve obtained using the total ground motion records considered in the study. The grey lines represents the attenuation curves obtains from 100 bootstrap samples. 


\subsubsection{Quality factor $\left(\mathbf{Q}_{s}\right)$ estimation}

In order to estimate, attenuation curves within the hypocentral distance in the range $15 \mathrm{~km}$ to $105 \mathrm{~km}$, (where a monotonic decrease of $\ln A\left(f, R_{i j}\right)$ with hypocentral distance is observed in Figure 4 is considered. Each of the attenuation curves shown in Figure 4 is modelled in terms of geometric spreading $\left[G\left(f, R_{i j}\right)\right]$ and quality factor $\left(\mathrm{Q}_{s}\right)$ [as per Castro et al. 1996] as:

$$
A\left(f, R_{i j}\right)=G\left(f, R_{i j}\right)\left[e^{\frac{-\pi \cdot f \cdot R_{i j}}{Q_{s} \beta}}\right]
$$

Where, $f$ is the frequency under consideration and $\beta$ is the mean shear wave velocity in the crustal medium which is taken as $3.5 \mathrm{~km} / \mathrm{s}$ for the study area after Mukhopadhyay and Kayal, [2003]. It has to be noted here that a trade-off exist between $\mathrm{Q}_{s}$ and $\mathrm{G}(\mathrm{f}, \mathrm{R})$ given in Eq. 3 [Oth et al. 2011]. For this reason it is difficult to derive a reliable estimate of and simultaneously. Moreover, the parts of the attenuation curves are more likely to be dominated by direct wave propagation as stated by Oth et al. [2011]. For this reason, in the present study the discussion is restricted to the estimation of $Q_{s}$ considering $G\left(f, R_{i j}\right)=1 / R_{i j}$ [in accordance with Parvez et al., 2012 for this region]. Detailed discussion on the determination of $\mathrm{Q}_{s}$ is given below.

For each of the 17 selected frequencies (see Table 4), Eq. (3) is linearized by taking logarithm on both sides and corrected for the effect of $G\left(R_{\mathrm{ij}}\right)$ as given in Eq. (4).

$$
\ln A\left(f, R_{i j}\right)=\ln G\left(R_{i j}\right)-\frac{-\pi \cdot f}{Q_{s} \beta} R_{i j}
$$

Rearranging Eq. (4) gives:

$$
\ln A\left(f, R_{i j}\right)-\ln G\left(R_{i j}\right)=\frac{-\pi \cdot f}{Q_{s} \beta} R_{i j}
$$

Ascribed to Castro et al. [2003], Eq. (5) is written in the form;

$$
\mathrm{a}(\mathrm{R})=-\mathrm{m} R
$$

Where $\mathrm{a}(\mathrm{R})$ and $\mathrm{m}$ are given as;

$$
\begin{gathered}
a(R)=\ln A\left(f, R_{i j}\right)-\ln G\left(R_{i j}\right) \\
m=\frac{-\pi \cdot f}{Q_{s} \beta}
\end{gathered}
$$

Where, $\mathrm{m}$ in Eq. (6) represents the slope between $\mathrm{a}(\mathrm{R})$ and $\mathrm{R}$ which for each of the selected 17 frequencies, is calculated based on a linear least-square fit. Further, $Q_{s}$ values are estimated for each of the selected frequencies by substituting the value of $\mathrm{m}$ in Eq. (8). Table 4 list the values of $\mathrm{m}$ and $\mathrm{Q}_{s}$ respectively. In order to develop the frequency dependent relationship of the form; $Q_{s}=Q_{0} f^{n}$, above estimated values of $Q_{s}$ are fitted as a function of frequency using a power law. In this expression, $Q_{0}$ is the $Q_{s}$ at $1 \mathrm{~Hz}$ frequency and $n$ is the frequency dependent coefficient, which is approximately equal to 1 and varies with heterogeneity of the medium [Aki, 1980]. Variation of $Q_{s}$ versus $f$ as illustrated in Figure 6 gives the following correlation for the northwest Himalayas as;

$$
Q_{s}=(105 \pm 11) f^{(0.94 \pm 0.08)}
$$




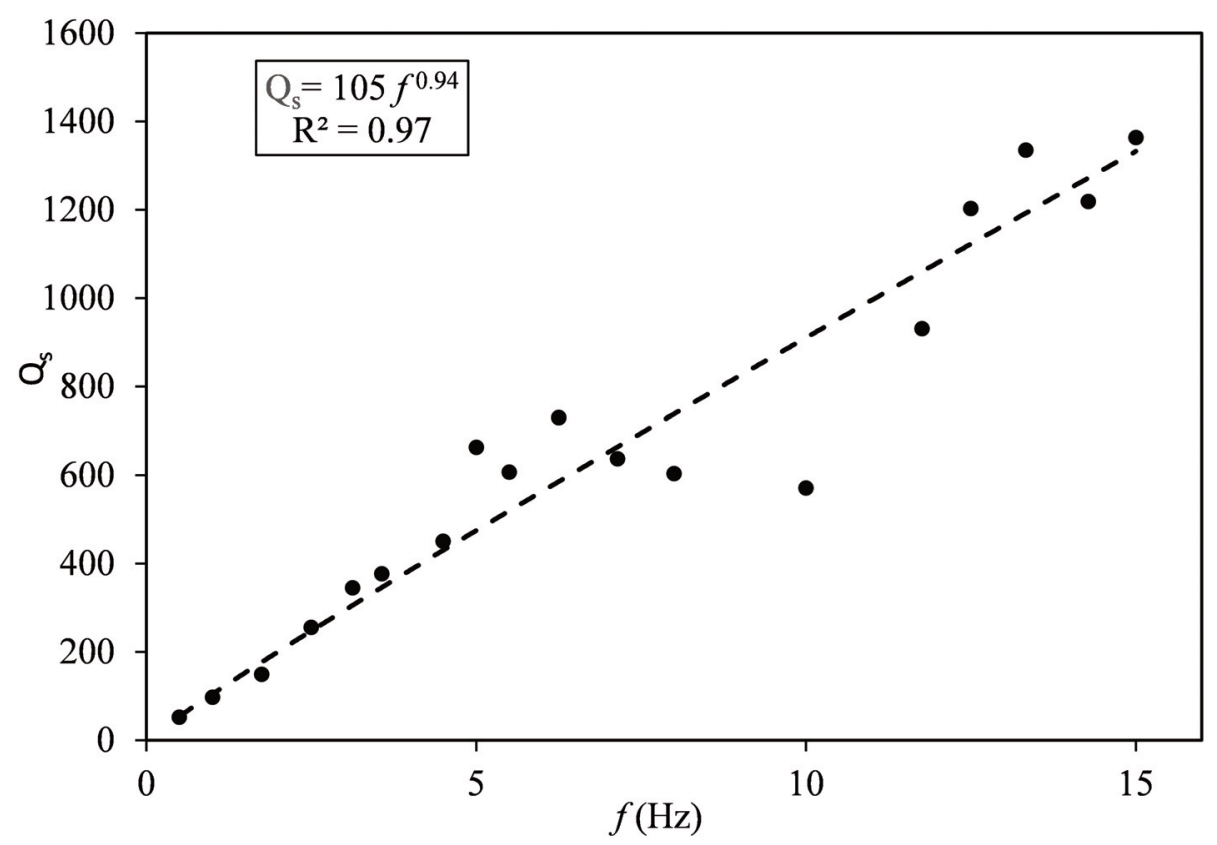

Figure 6. Frequency dependence of the quality factor $\mathrm{Q}_{S}$.

It has to be emphasised here that the $Q_{s}$ estimated in the present study is based on the assumption of $G\left(f, R_{i j}\right)=$ $1 / \mathrm{R}_{\mathrm{ij}}$, and Eq. 9 is only valid under this assumption.

Values of $Q_{0}$ and (in the expression $Q_{s}=Q_{0} f^{n}$ )are attributed to the level of tectonic activity and degree of medium heterogeneity respectively, present in the region. Aki, [1980] concluded higher values of for tectonically active regions in comparison to that of stable regions. Similarly, low value of $\mathrm{Q}_{0}(<200)$ is an indication of larger degree of heterogeneities in the medium [Joshi, 2006]. The values of $n(=0.94)$ and $\mathrm{Q}_{0}(=105)$, obtained in this study indicate that the present study region is tectonically active, characterized by higher degree of heterogeneities. Previous study by Kumar et al. [2005] also reveals a higher degree of heterogeneity in the crustal medium of north-west Himalayas based on studying the lapse time dependence of the Coda $Q_{(}\left(Q_{C}\right)$ in the frequency range $1.5 \mathrm{~Hz}$ to $18 \mathrm{~Hz}$.

\subsubsection{Comparison with regional and global attenuation characteristics}

As previously discussed, numerous studies exist where path attenuation of different parts of the present study area were attempted in the past. Comparison of present results with those obtained by the previous researchers for the north-west Himalayas and Delhi region is attempted as shown in Figure 7. It can be seen from Figure 7 that the attenuation curve obtained in the present study falls in between existing attenuation curves for the different parts of the north-west Himalayas as given in the literature [Kinnaur, Kumar et al. 2009; Kumoan, Mukhopadhyay et al. 2010; Garhwal regions, Negi et al. 2015; and Delhi, Sharma et al. 2015]. It has to be highlighted here that the database for the present study also includes EQ records from Kinnaur, Kumoan, Garhwal regions of the north-west Himalayas as well as from regions in and around Delhi. For this reason, the value of $\mathrm{Q}_{0}$ and $\mathrm{n}$ obtained in the present study reflects an average attenuation characteristics of regions encompassing north-west Himalayas up to Delhi region within Indian boundary as shown in Figure 7.

Furthermore, the attenuation results obtained in this study is compared with some typical results obtained globally in terms of attenuation characteristics and tectonic setting as shown in Figure 8. Literature suggests low values of $Q_{s}$ for tectonically active regions [e.g. Kato Japan region, Yoshimoto et al. 1993; East central Iran, Mahood et al., 2009; Egypt, Abdel, 2009; Umbria-Marche region, Lorenzo et al., 2013] and South eastern Tibet Wang et al., 2018]. Similarly, relatively high values of $Q_{s}$ were reported for tectonically stable areas [e.g. Baltic Shield, Kvamme and Havskov, 1989; Central South Korea, Kim et al., 2004 and South Eastern Korea, Chung and Sato, 2001]. It can be observed from Figure 8 that the obtained relation $Q_{s}=(105) f^{(0.94)}$ for the present study region complies with similar relations obtained for other tectonically active regions. 


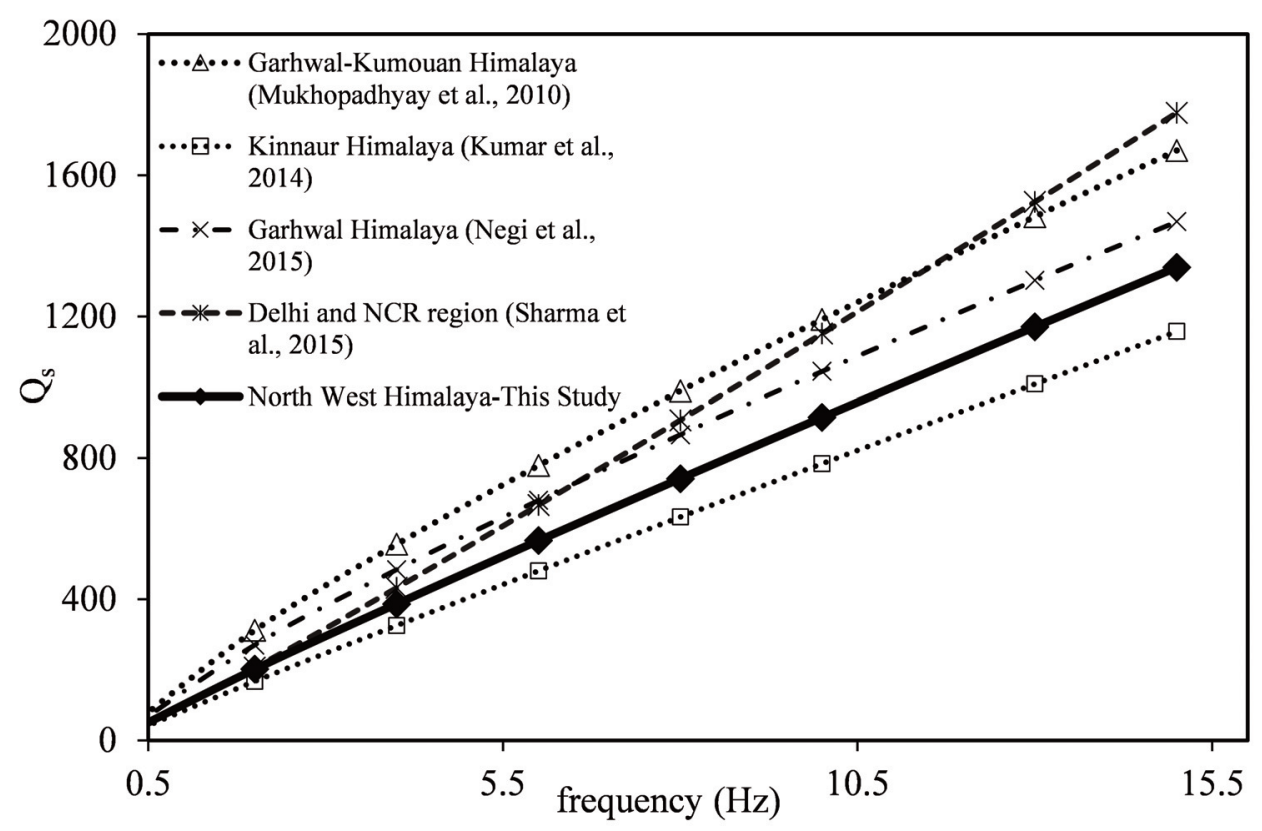

Figure 7. Comparison of $\mathrm{Q}_{S}$ values of North West Himalaya with those obtained from parts of North West Himalaya and Delhi region (Compared relations for Qs versus frequency are as follows: Garhwal-Kumouan Himalaya: $\mathrm{Q}_{S}=175 \mathrm{f}^{0.833}$ [Mukhopadhyay et al. 2010]; Kinnaur Himalaya: $Q_{S}=86 \mathrm{f}^{0.96}$ [Kumar et al. 2014]; Garhwal Himalaya: $Q_{S}=151 f^{0.84}$ [Negi et al. 2015]; Delhi and NCR region: $Q_{S}=98 f^{1.07}$ [Sharma et al. 2015].

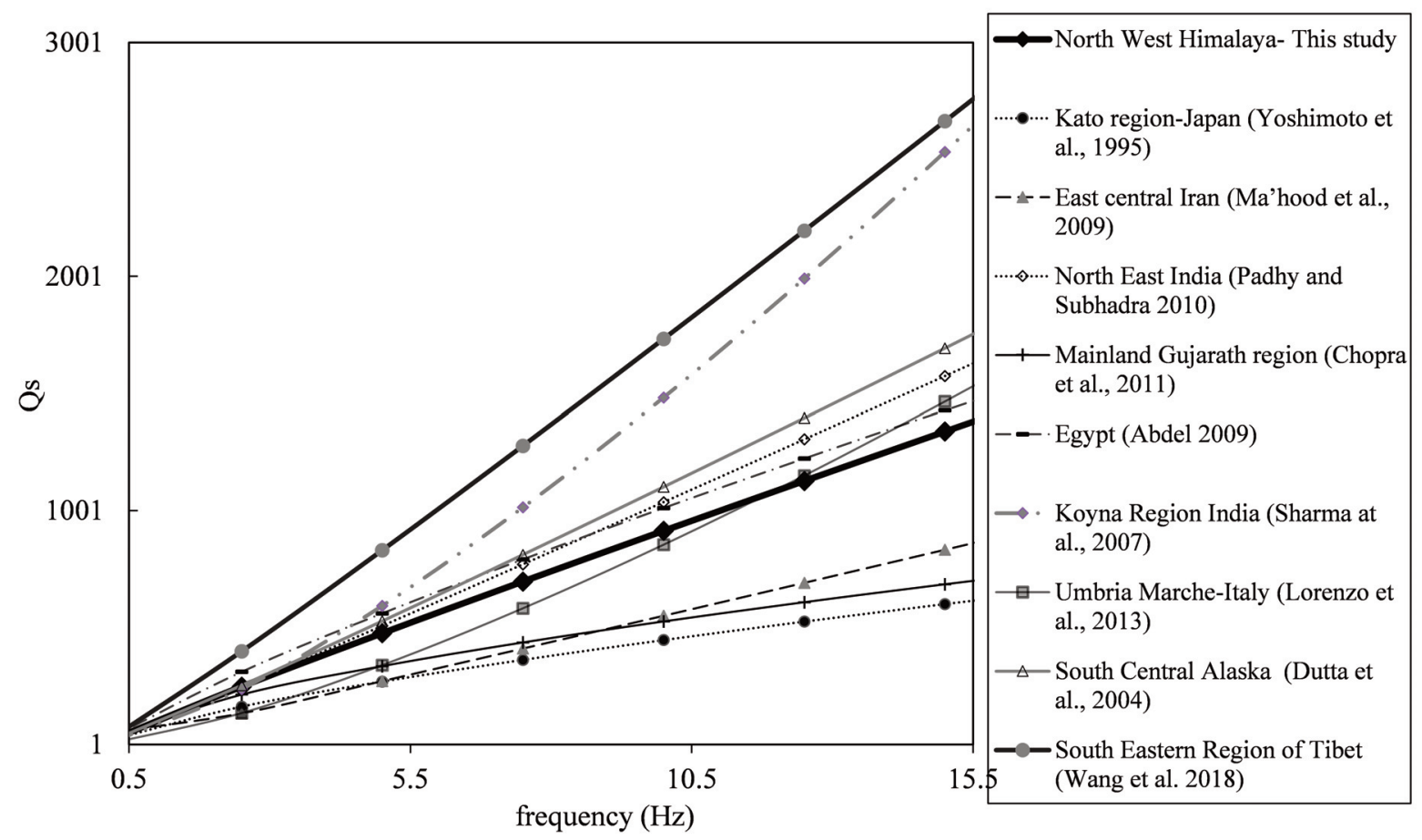

Figure 8. Comparison of $\mathrm{Q}_{\mathrm{S}}$ values of this study with regions of different tectonic settings of the world (Compared relations for Qs versus frequency are as follows: Kato region - Japan: $\underline{Q}_{S}=83.33 f^{0.73}$ [Yoshimoto et al. 1993]); East Central Iran: $Q_{S}=52.63 f^{1.02}$ [Ma'hood et al. 2009]; North East India: $Q_{S}=96.8 f^{1.03}$ [Padhy and Subhadra, 2010]; Main Land Gujarath: $Q_{S}=118 f^{0.65}$ [Chopra et al. 2011]; Egypt: $Q_{S}=143 f^{0.85}$ [Abdel, 2009]; Koyna Region India: $Q_{S}=71 f^{1.32}$ [Sharma at al., 2007]; Umbria-Marche Italy: $Q_{S}=40 f{ }^{1.33}$; South Central Alaska: $Q_{S}=96 f f^{1.06}$ [Dutta et al. 2004]; South Eastern Region of Tibet: $Q_{S}=151.2 f^{1.06}$ [Wang et al. 2018]. 


\section{Nelliparanbil Hareeshkumar Harinarayan and Abhishek Kumar}

\section{Site effects}

As highlighted earlier, site characteristics of the recording stations are determined in the second step of inversion, which is discussed in this section. These are estimated based on both inversion and HVSR methods in this work and are compared. Detailed discussion on the GINV and HVSR is given in the subsequent sections.

\subsection{GINV}

GINV was originally developed by Andrews [1986] by improvising spectral ratio method of Borcherdt (1970). Since then, various forms of this technique have been developed and used for estimating the seismic site characteristics by various researchers [Castro et al., 1990; Boatwright et al., 1991; Oth et al., 2008 etc.]. Methodology used in the present study for estimating site characteristics is as follows;

As per Andrews, [1986], the Fourier amplitude of the S-wave portion of the accelerogram [U(f $\left.)_{i j}\right]$ of the $j^{\text {th }} \mathrm{EQ}$, recorded at the $\mathrm{i}^{\text {th }}$ recording station, can be represented in the frequency domain as the product of source term $\left[\mathrm{S}(\mathrm{f})_{\mathrm{j}}\right]$, path attenuation $\left[\mathrm{A}(\mathrm{f})_{\mathrm{ij}}\right]$ and site term $\left[\mathrm{G}(\mathrm{f})_{\mathrm{i}}\right]$ as;

$$
\mathrm{U}(\mathrm{f})_{\mathrm{ij}}=\mathrm{S}(\mathrm{f})_{\mathrm{j}} \mathrm{A}(\mathrm{f})_{\mathrm{ij}} \mathrm{G}(\mathrm{f})_{\mathrm{i}}
$$

The path attenuation term can be removed from the spectral content of the record following Andrews, (1986) as;

$$
U^{A}(f)_{i j}=\frac{U\left(f \left(f_{i j}\right.\right.}{A(f)} S(f)_{j} G(f)_{i}
$$

The value of A(f $)_{i j}$ in Eq. (10) can be estimated using Eq. (3) and above calculated $Q_{s}$ (refer to Eq. 9). Further, Eq. (11) can be linearized [as per Andrews, 1986] by taking natural logarithms on both sides giving;

$$
\ln U^{A}(f)_{i j}=\ln S(f)_{j}+\ln G(f)_{i}
$$

For a particular recording station, let: $\ln S(f)_{j}=s_{j}(f), \ln G(f)=g(f)$ and $\ln U^{A}(f)_{j}=d_{j}(f)$, Eq. (12) in accordance with Joshi et al. (2010) and following the notations of Menke, [1989] in the matrix form can be written as;

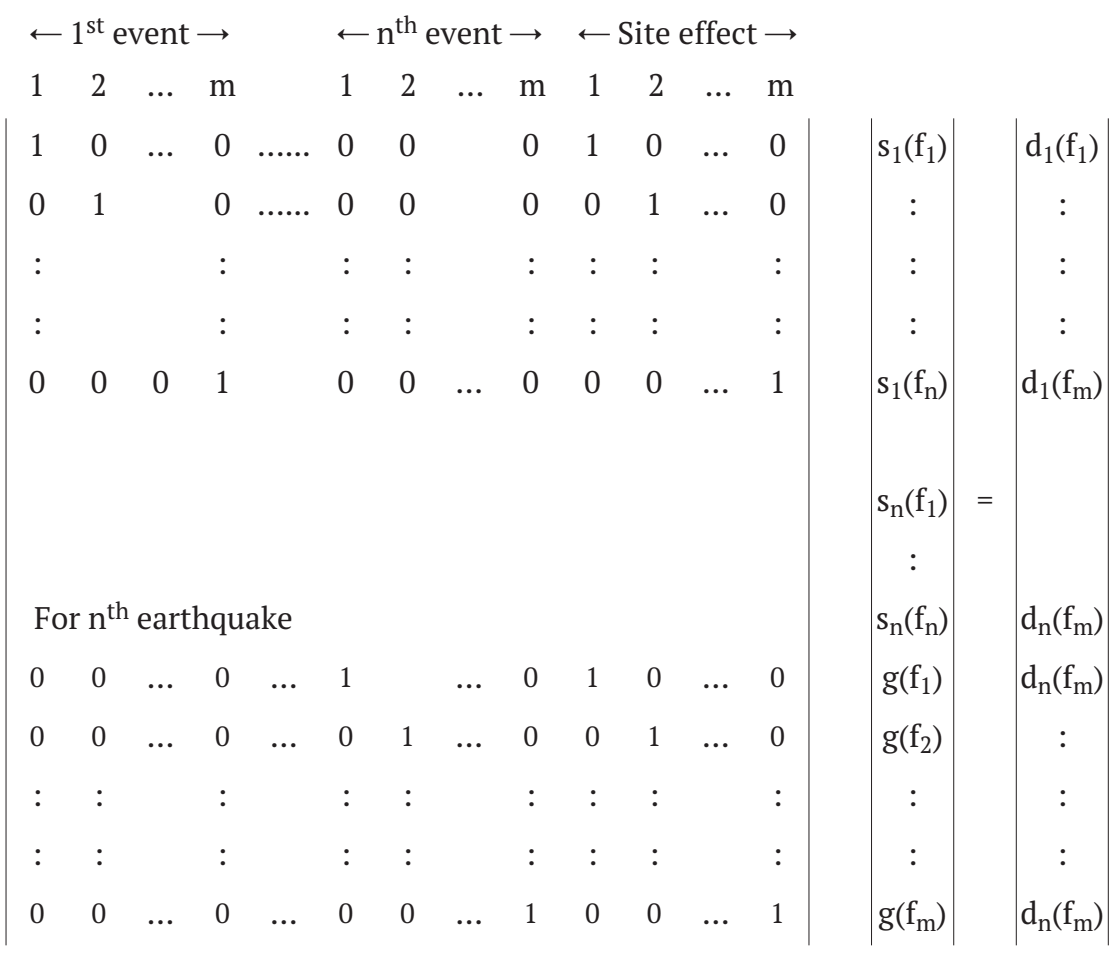


Eq. (13) represents a purely under-determinate system since there are $(n+1) \times m$ unknowns for " $m \times n$ " data (here $\mathrm{m}$ is the number of sample frequency and is the number of EQs recorded at a particular recording station). In this work, Eq. (13) is solved using Moore-Penrose matrix inversion procedure (minimum norm inversion) given by Penrose, [1955] to determine $\mathrm{g}(\mathrm{f})$ for each of the recording stations.

\subsection{HVSR}

HVSR method is an extension of Nakamura, (1989) technique, which is widely used to assess the subsoil characteristics using recorded ambient noises. Nakamura, (1989) technique is based on the assumption that the soil amplification effects are retained only in the horizontal component whereas the source and the path effects are maintained both in vertical as well as horizontal components of ground motion. Hence, the ratio of horizontal and vertical components gives an estimate of site amplification. Lermo and Chavez-Garccia, [1993] extended Nakamura, (1989) technique to S-wave part of the accelerograms and studied the theoretical basis of the technique by numerical modelling of SV waves. Later, HVSR method was applied to EQ recordings worldwide [Luzi et al., 2011; YaghmaeiSabegh and Tsang, 2011; D’Alessandro et al., 2012; Harinarayan and Kumar, 2017a, b, 2018 etc.] to obtain the site characteristics.

Comparative studies between HVSR and other methods of evaluating site parameters reported by Field and Jacob, [1995], Parolai et al. [2004], Shoji and Kamiyama [2002], Harinarayan and Kumar, [2017b] etc. show that, HVSR can provide good and reliable estimate of predominant frequency. However, above literatures also point out discrepancies in amplification levels obtained from HVSR and other methods. In order to compare the site amplification functions obtained from HVSR and GINV methods, same S-wave portion of the accelerogram is used in HVSR as well as in GINV in this paper. HVSR curve for each recording station is determined [similar to Harinarayan and Kumar, 2018] using the following steps;

1) Calculate the response spectra considering $5 \%$ damping, for all the three components (north-south, east-west and vertical) of ground motion records.

2) Obtain the geometric mean of the two horizontal response spectra components (H) using Eq. (14) given below;

$$
\mathrm{H}=\left(\mathrm{H}_{\mathrm{EW}} \times \mathrm{H}_{\mathrm{NS}}\right)^{0.5}
$$

3) Calculate the ratio of $\mathrm{H}$ to $\mathrm{V}(\mathrm{H} / \mathrm{V})$.

Where, $\mathrm{H}_{\mathrm{EW}}$ and $\mathrm{H}_{\mathrm{NS}}$ are the response spectrum of the horizontal east-west and north-south components respectively and $\mathrm{V}$ is the response spectrum corresponding to vertical component of ground motion. Then, the HVSR at each of the recording station can be estimated as;

$$
(H V S R)_{i}=\frac{\sum_{i=1}^{N i} \frac{H}{V}}{N_{i}}
$$

Here, $\mathrm{N}_{\mathrm{i}}$ is the number of events recorded at recording station " $\mathrm{i}$ " and (HVSR) $)_{\mathrm{i}}$ indicates the average HVSR value for a particular recording station " $i$ ". The $f_{\text {peak }}$ is the value of frequency corresponding to a maximum value of $\mathrm{HVSR}_{i}$ (denoted by $\mathrm{A}_{\text {peak}}$ ) at the recording station " $\mathrm{i}$ " which is also known as the predominant frequency of the recording station.

\subsection{Site parameters}

Site spectral amplitude (SSA) curves are developed using GINV for the horizontal (GINV H) and the vertical (GINV V) components separately. Figure 9 (a-f) shows typical amplification curves obtained for GINV H (indicated by dashed lines) and GINV V (indicated by firm lines) for 6 typical recording stations based on present analysis. In general, obtained amplification values from GINV H are higher than GINV V for all frequencies (see Figure 9a-f). 


\section{Nelliparanbil Hareeshkumar Harinarayan and Abhishek Kumar}

A typical observation (from Figure 9a-f) for both GINV H and GINV V is that the high level of amplitude is observed at high frequencies. For given recording stations, a clear and distinct peak in the SSA curve can be observed (e.g. JAMI, BAR, GHA and SND in Figure 9a-f). Moreover, the peaks of the GINV V component are at frequencies higher than that for the GINV H component. Based on obtained GINV H and GINV V, site amplification factor $(\mathrm{H} / \mathrm{V})$ is estimated (denoted by GINV H/V) as the ratio of GINV H to GINV V. Results of GINV H/V curves are compared with those estimated using HVSR method for a total of 101 recording stations. Figure 10(a-i) shows the comparison in terms of H/V obtained from HVSR (indicated by dashed lines) and GINV H/V (indicated by firm line) for a typical 9 recording stations from the present analyses. A general observation which can be drawn from Figure 10(a-i) is that both HVSR and GINV H/V show similar H/V patterns for all recording stations in the selected frequency range. Similar observation is drawn for each of the 101 recording stations.

Identification of the value of $\mathrm{f}_{\text {peak }}$ from GINV H/V curve is carried out in accordance with Ren at al. [2018], who classified GINV H/V curves into three categories. In the first category, GINV H/V curves have only one peak and the frequency at the peak is classified as $\mathrm{f}_{\text {peak }}$. In the second category, GINV $\mathrm{H} / \mathrm{V}$ curves have more than one peak and the smaller peak is classified as $\mathrm{f}_{\text {peak }}$. In the third category, GINV H/V curves appears flat, indicating peak is unidentifiable. Site classification is not attempted for recording stations having flat GINV H/V curves. Based on the above discussion $\mathrm{f}_{\text {peak }}$ for all the recording stations are identified in this study. For each recording station, values of $\mathrm{f}_{\text {peak }}$ obtained from GINV H/V and HVSR methods exhibit 1:1 (see Figure 11) matching (typical observations can be made from Figure 10a-i). However, there is difference in terms of $A_{\text {peak }}$ values obtained based on GINV H/V and HVSR. $A_{\text {peak }}$ values obtained using HVSR are found to be higher in comparison to those obtained using GINV H/V. Similar observations were also reported for other regions [Sharma et al., 2014; Field and Jacob, 1995]. Values of $\mathrm{f}_{\text {peak }}$ obtained using GINV H/V and HVSR are tabulated in Table 1 respectively. Similarly, the values of $\mathrm{A}_{\text {peak }}$ obtained using GINV H/V and HVSR are tabulated in Table 1 respectively.
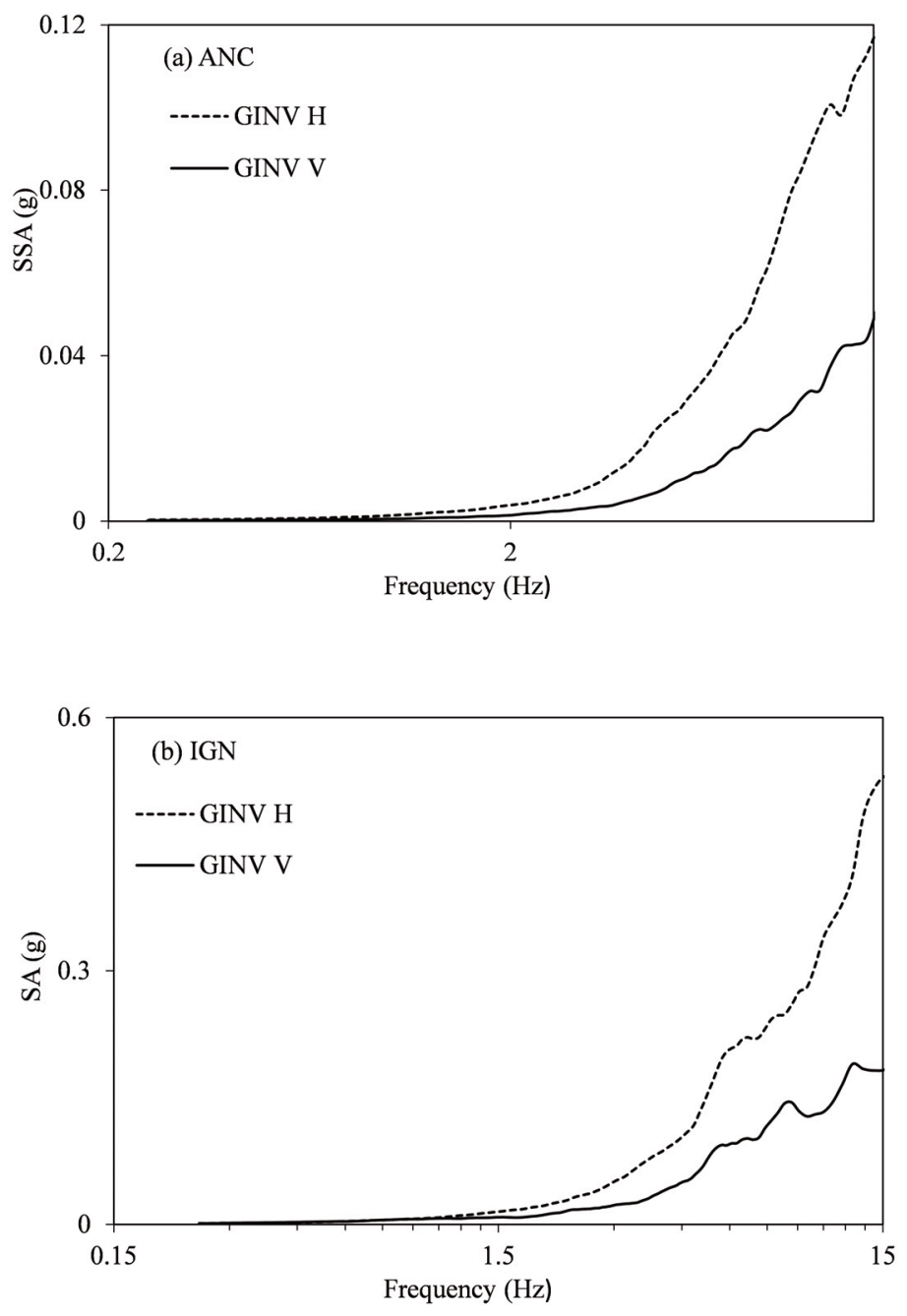
Path and Site Characteristics
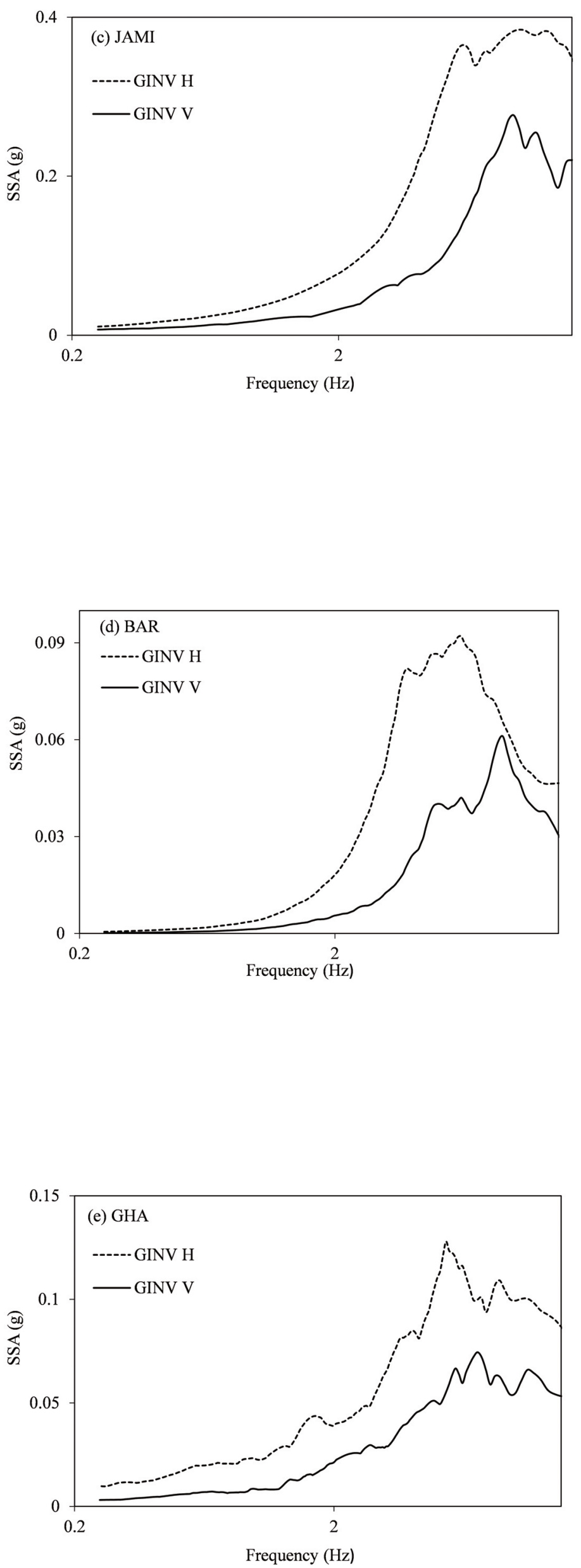


\section{Nelliparanbil Hareeshkumar Harinarayan and Abhishek Kumar}

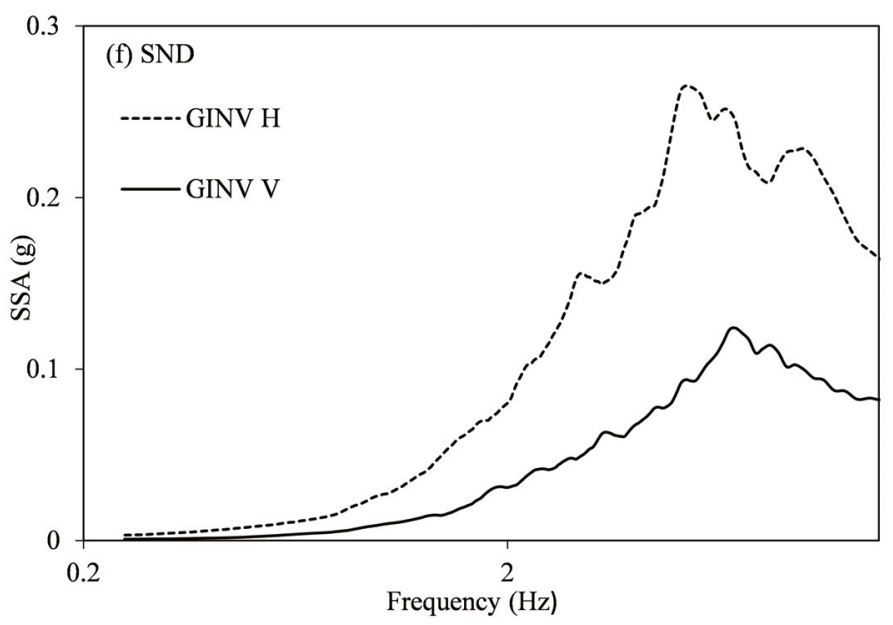

Figure 9. (a-f) Site spectral amplitude curves obtained using GINV for horizontal component and vertical component.

Further, based on the values of $\mathrm{f}_{\text {peak }}$ obtained using $\mathrm{H} / \mathrm{V}$ curves, each of the 101 recording stations are classified following NEHRP (BSSC, 2000) site classification scheme. NEHRP classifies a site based on 30m average shear wave velocity $\left(\mathrm{V}_{\mathrm{S} 30}\right)$. The range of $\mathrm{f}_{\text {peak }}$ values corresponding to the range of $\mathrm{V}_{\mathrm{S} 30}$ values for different NEHRP site classes is calculated using Eq. (16) following Kramer [1996] with depth of soil column considered as 30m.

$$
\mathrm{f}_{\text {peak }}=\mathrm{V}_{\mathrm{z}} / 4 \mathrm{H}
$$

Where, $\mathrm{Vz}$ is the shear wave velocity, $\mathrm{H}$ is the thickness which is considered as $30 \mathrm{~m}$ in this study following NEHRP site classification scheme. The ranges of $f_{\text {peak }}$ for various SC are tabulated in Table 5. Based on the values of $f_{\text {peak }}$ obtained using H/V earlier for each of the 101 recording stations, SCs are proposed as listed in Table 1. Based on SC determination from this work, it can be summarized that out of total 101 recording stations, 2, 10, 29, 33, and 27 numbers of recording stations belong to NEHRP SC A, B, C, D and E respectively.

\subsection{Empirical correlation between $\mathrm{f}_{\text {peak }}$ and $\mathrm{V}_{\mathrm{S} 30}$}

SCs for the recording stations, as discussed in section 5.3, are done assuming the depth of overburden to be $30 \mathrm{~m}$ following NEHRP site classification scheme. In actual site however, this depth of overburden, whose response is observed in Figure 10 may vary from 30m. Thus, in order to check the suitability of Kramer [1996] correlation between $\mathrm{f}$ and $\mathrm{V}_{\mathrm{Z}}$ (Eq. 16) for the present study area, assuming $30 \mathrm{~m}$ soil column depth, comparison of Vs30 values obtained as per Eq. (16) and $\mathrm{V}_{\mathrm{S} 30}$ determined based on in-situ tests for typical recording stations which are the part of present database is done. Pandey et al. [2016a, b] determined $\mathrm{V}_{\mathrm{S} 30}$ for 8 recording stations in Tarai region of Uttarakhand and 19 recording stations in Delhi region based on in-situ Multichannel Analysis of Surface Wave (MASW) tests. All these 27 recording stations are part of present 101 recording stations. $\mathrm{V}_{\mathrm{S} 30}$ [obtained from Pandey et al., $2016 \mathrm{a}, \mathrm{b}$ ] and $\mathrm{f}_{\text {peak }}$ (as per present work) for above 27 recording stations are listed in Table 6. These values of $\mathrm{V}_{\mathrm{S} 30}$ and corresponding $\mathrm{f}_{\text {peak }}$ are presented in Figure 12 . Another set of values of $\mathrm{V}_{\mathrm{S} 30}$, assuming $30 \mathrm{~m}$ as soil column depth, as obtained from Eq. (16), for same 27 recording stations are also presented in Figure 13 with corresponding $\mathrm{f}_{\text {peak }}$ which is used earlier to determine SC (section 5.3). Comparison of two set of data in Figure 11 clearly indicates that $\mathrm{V}_{\mathrm{S} 30}$ values in absence of actual subsoil depth information, as obtained from can be used for SC determination for the present study area.

Another correlation based on $\mathrm{V}_{\mathrm{S30}}$ as per Pandey et al., [2016a,b] and $\mathrm{f}_{\text {peak }}$ from present work, as available for above mentioned 27 recording stations is attempted as shown in Figure 13. In absence of any functional form of correlation between the two in literature, following empirical correlation is obtained based on highest $\mathrm{R}^{2}$ value as; 


$$
\log f_{\text {peak }}=(1.5 \pm 0.18)\left(\log \mathrm{V}_{S 30}\right)-(3.3 \pm 0.5)
$$

It has to be highlighted here that Eq. (17) is applicable for sites having $\mathrm{f}_{\text {peak }}$ in the range 1.8 to $6 \mathrm{~Hz}$ and $\mathrm{V}_{S 30}$ in the range $198 \mathrm{~m} / \mathrm{s}$ to $565 \mathrm{~m} / \mathrm{s}$.
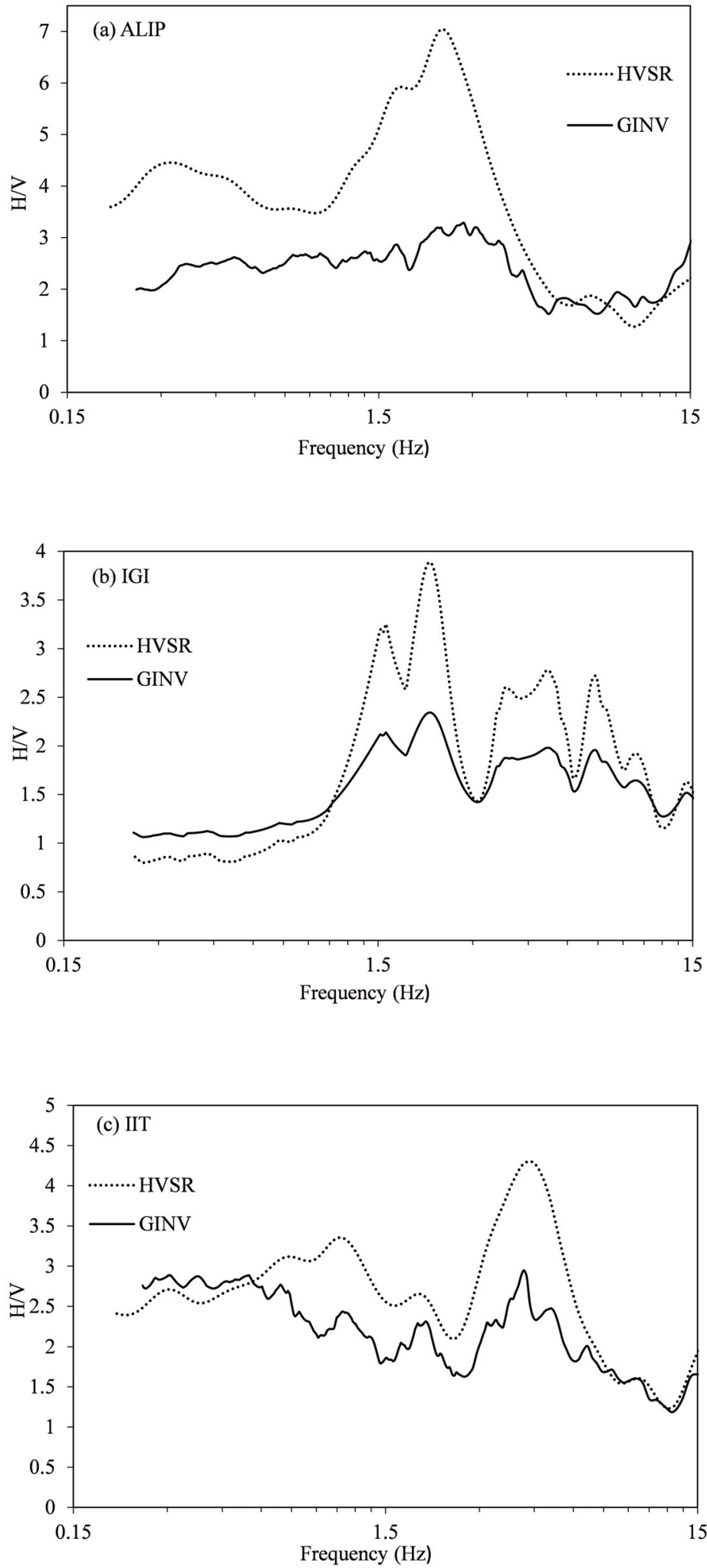

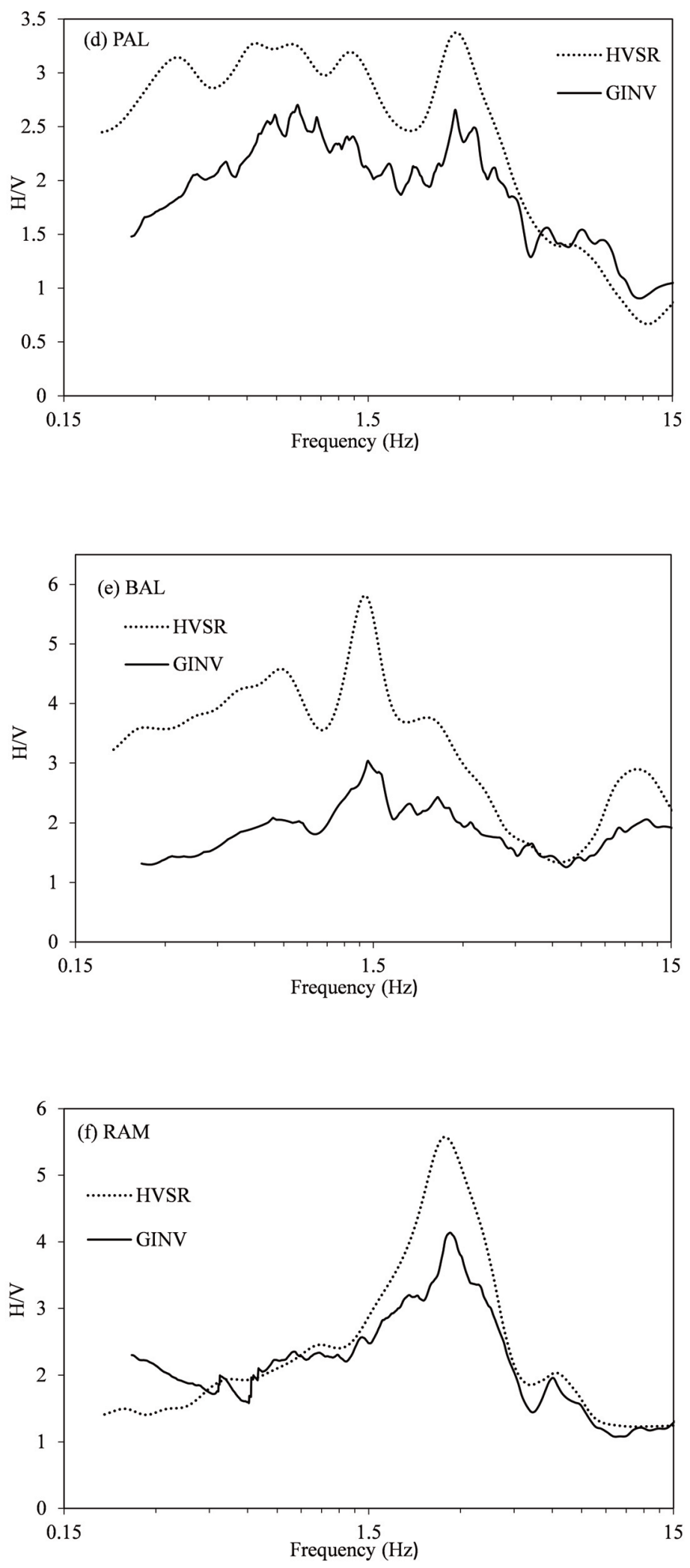

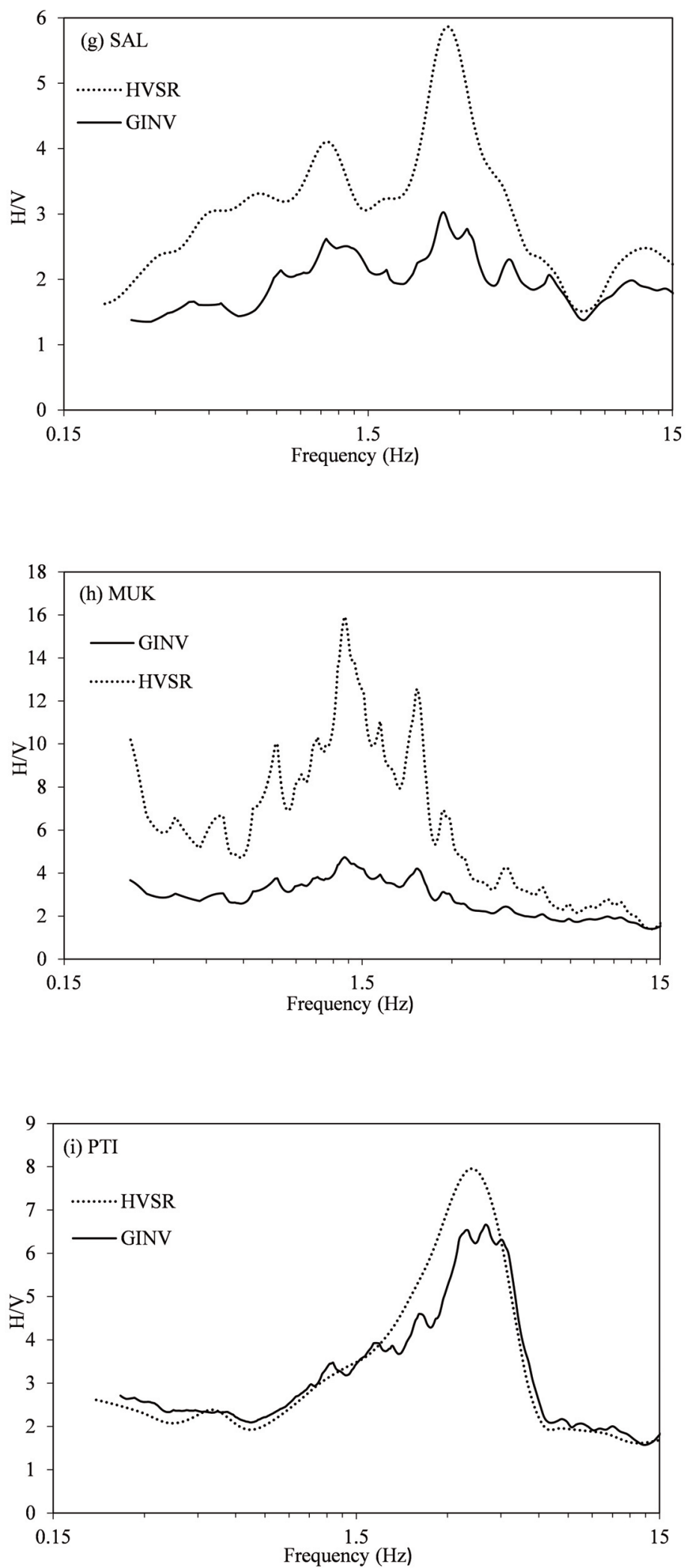

Figure 10. (a-i) Horizontal to vertical ratio curve obtained using GINV and HVSR method. 
Nelliparanbil Hareeshkumar Harinarayan and Abhishek Kumar

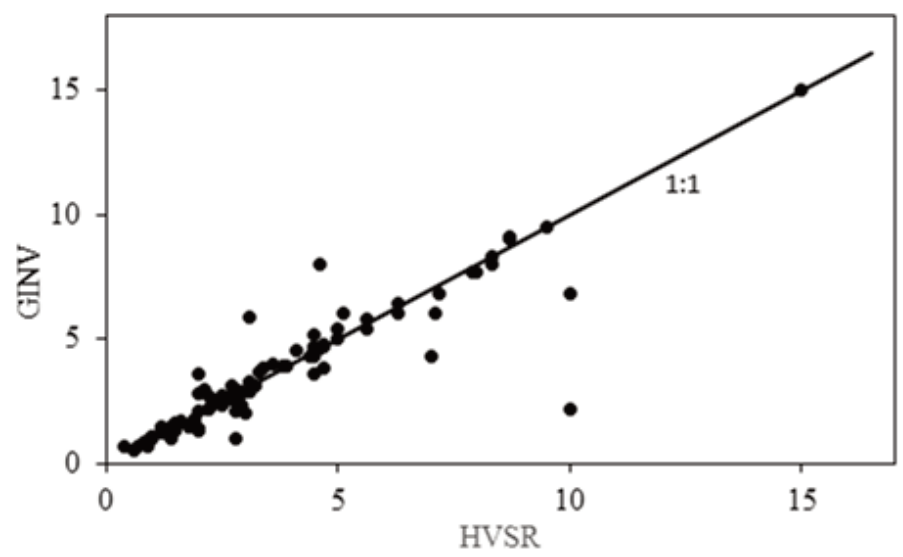

Figure 11. Comparison of the value $\mathrm{f}_{\text {peak }}$ obtained from Horizontal to Vertical Spectral Ratio and Generalized Inversion methods.

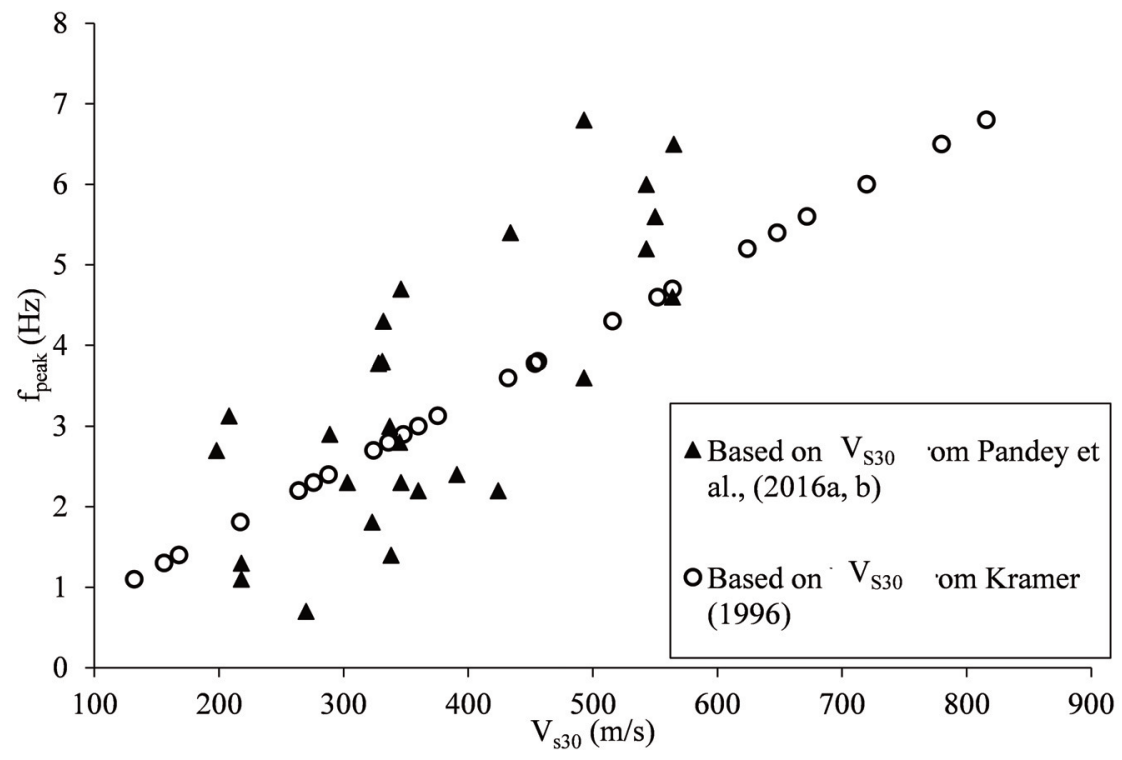

Figure 12. Comparison of $\mathrm{V}_{\mathrm{S} 30}$ for 27 recording stations as per Pandey et al., (2016a, b) and based on Kramer [1996].

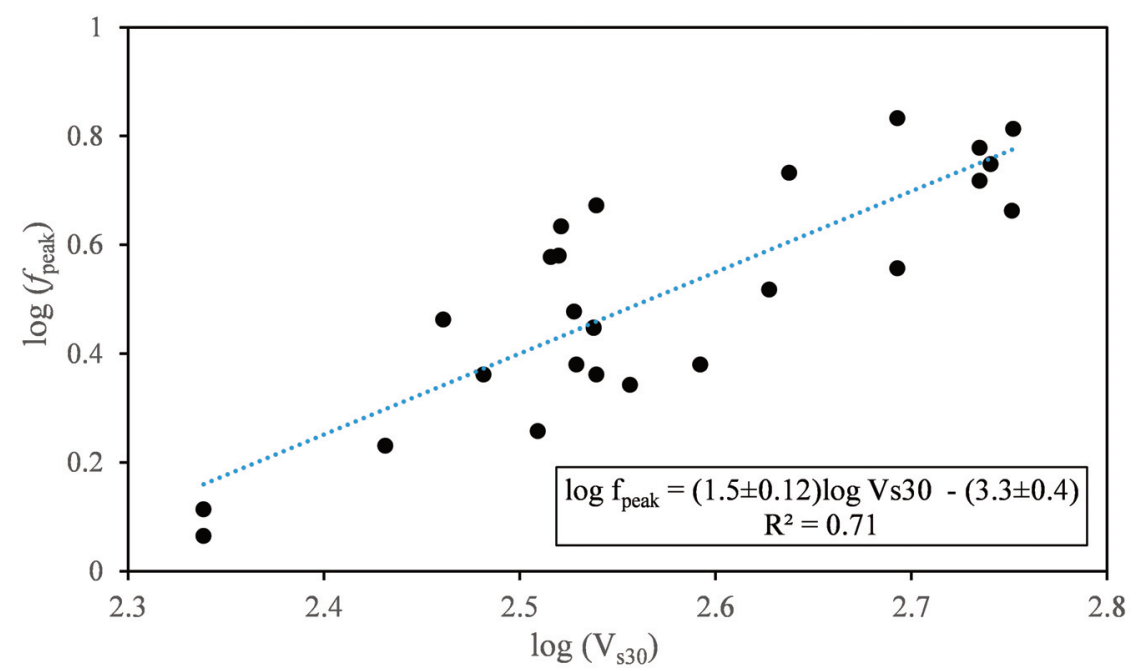

Figure 13. $V_{\mathrm{s} 30}$ as a function of $\mathrm{f}_{\text {peak }}(\mathrm{a})$ and $\mathrm{A}_{\text {peak }}(\mathrm{b})$ of GINV method for recording stations at Delhi and Tarai region of Uttarakha. 


\section{Conclusion}

In the light of on-going seismicity and catastrophic damages witnessed during earlier EQs, of path attenuation as well as site characterization of PESMOS handled EQ recording stations, located in the north-west Himalayas and adjoining area of is attempted. Dataset for the analysis consists of ground motion records from EQs happened between 2004 and 2017. Entire analysis is done based on two-step inversion. While determining path attenuation in first step, a kink in path attenuation curve at $105 \mathrm{~km}$ hypocentral distance is observed. Referring to similar observations from other regions, presence of Moho discontinuity is proposed in the region. However, such finding must be validated based on detailed study which is beyond the scope of present work's objective. Further, based on attenuation curve obtained till $105 \mathrm{~km}$ hypocentral distance and over wide range of frequencies $(0.05-15 \mathrm{~Hz}), \mathrm{Q}_{\mathrm{S}}=(105 \pm 11) \mathrm{f}^{(0.94 \pm 0.08)}$ is obtained for the present study area, clearly indicating that the region is heterogeneous and seismically active. It has to be highlighted here that dataset used in present analysis covers a much larger range of ground motion records in the analysis in comparison to earlier studies attempted for some part of present study area.

In absence of proper geological information of PESMOS recording stations as highlighted by numerous recent studies, predominant frequency of each of the 101 recording stations are calculated based on GINV as well as HVSR and are found matching for all the stations. Based on predominant frequency values for each recording station, SCs of 101 recording stations located within present study area, are proposed. Based on proposed site class, out of total 101 recording stations, 2, 10, 29, 33, and 27 numbers of recording stations are found belonging to NEHRP SC A, B, $\mathrm{C}$, D and E respectively. It has to be highlighted here that unless the SC of recording station is known, ground motion records from a recording station cannot be used confidently for development of regional ground motion prediction equation or for region specific ground response analysis.

Both path attenuation and site characteristics, determined in the present work, are the key factors in developing regional ground motion models and are important inputs for seismic hazards studies. Without proper knowledge of above two parameters on regional level, suitability of developed ground motion prediction equation as well as seismic scenario to capture correct seismicity will be debatable.

Acknowledgement. The authors would like to thank the INSPIRE Faculty program by the Department of Science and Technology (DST), Government of India for the funding project "Propagation path characterization and determination of in-situ slips along different active faults in the Shillong Plateau" ref. no. DST/INSPIRE/04/2014/002617 [IFA14-ENG104] for providing necessary funding and motivation for the present study.

\section{Reference}

Ambraseys, N. and R. Bilham (2000). A note on the Kangra $\mathrm{M}_{\mathrm{S}}=7.8$ earthquake of 4 April 1905, Current Science, 79(1), 45-50.

Abdel-Fattah A.K. (2009). Attenuation of body waves in the crust beneath the vicinity of Cairo Metropolitan area (Egypt) using coda normalization method, Geophys J. Int., 176(1), 126-134.

Aki, K., (1980). Attenuation of shear-waves in the lithosphere for frequencies from 0.05 to $25 \mathrm{~Hz}$, Phys. Earth Planet Inter., 21, 50-60.

D’Alessandro C., L.F. Bonilla, D.M. Boore, A. Rovelli and O. Scotti (2012). Predominant-period site classification for response spectra prediction equations in Italy, Bull. Seismol. Soc. Am., 102(2), 680-695.

Ameri, G., A. Oth, M. Pilz, D. Bindi, S. Parolai, L. Luzi and G. Cultrera (2011). Separation of source and site effects by generalized inversion technique using the aftershock recordings of the 2009 L'Aquila earthquake. Bull. of Earthq. Eng., 9(3), 717-739.

Andrews, D.J. (1986). Objective determination of source parameters and similarity of earthquakes of different size, Earthq. Source Mechanics, 259-267.

Borcherdt, R.D. (1970). Effects of local geology on ground motion near San Francisco Bay, Bull. Seismol. Soc. Am., 60(1), 29-61.

Banerjee, S. and A. Kumar (2017). Determination of seismic wave attenuation for the Garhwal Himalayas, India, Geosci. Res., 2(2), 105-126. 


\section{Nelliparanbil Hareeshkumar Harinarayan and Abhishek Kumar}

Baro, O., A. Kumar and A.S. Zadeh (2018). Seismic hazard assessment of the Shillong Plateau, India, Geomatics Nat. Hazards and Risk, 9(1), 841-861.

Bilham, R., K. Larson and J. Freymueller (1997). GPS measurements of present-day convergence across the Nepal Himalaya, Nature, 386(6620), 61.

Bindi, D., R.R. Castro, G. Franceschina, L. Luzi and F. Pacor (2004). The 1997-1998 Umbria-Marche sequence (central Italy): Source, path, and site effects estimated from strong motion data recorded in the epicentral area, J. Geophys. Res. B: Solid Earth, 109(B4).

Bindi, D., F. Pacor, L. Luzi, M. Massa and G. Ameri (2009). The M w 6.3, 2009 L'Aquila earthquake: source, path and site effects from spectral analysis of strong motion data, Geophys. J. Int., 179(3), 1573-1579.

BSSC, (2003). Building Seismic Safety Council, NEHRP recommended provisions for seismic regulations for new buildings and other structures, Report FEMA-450 (Provisions), Federal Emergency Management Agency (FEMA), Washington.

Boatwright, J., J.B. Fletcher and T.E. Fumal (1991). A general inversion scheme for source, site, and propagation characteristics using multiply recorded sets of moderate-sized earthquakes, Bull. Seismol. Soc. Am., 81(5), 1754-1782.

Castro, R.R, J.G. Anderson and S.K. Singh (1990). Site response, attenuation and source spectra of S waves along the Guerrero, Mexico, subduction zone, Bull. Seismol. Soc. Am., 80(6A), 1481-1503.

Castro, R.R., H. Fabriol, M. Bour and B. Le Brun (2003). Attenuation and site effects in the region of Guadeloupe, Lesser Antilles, Bull. Seismol. Soc. Am., 93(2), 612-626.

Castro, R.R., F. Pacor, A. Sala and C. Petrungaro (1996). S wave attenuation and site effects in the region of Friuli, Ital,. J. Geophys. Res. B: Solid Earth, 101(B10), 22355-22369.

Chung, T.W. and H. Sato (2001). Attenuation of high-frequency P and S waves in the crust of southeastern South Korea, Bull. Seismol. Soc. Am., 91(6), 1867-1874.

De Lorenzo, S., E. Del Pezzo, and F. Bianco (2013). Qc, Q $\beta$, Qi and Qs attenuation parameters in the Umbria-Marche (Italy) region, Phys. Earth Planet Inter., 218, 19-30.

Dutta, U., N. Biswas, A. Martirosyan, A. Papageorgiou and S. Kinoshita (2003). Estimation of earthquake source parameters and site response in Anchorage, Alaska from strong-motion network data using generalized inversion method, Phys. Earth Planet Inter., 137(1-4), 13-29.

Geological Survey of India (GSI) (1998). Geological maps of India. Geological Survey of India, Kolkata.

Harinarayan, N.H. and A. Kumar (2017 a). Site classification of the strong motion stations of Uttarakhand, India, Based on the model horizontal to vertical spectral ratio, Geotechnical Frontiers, 141-149.

Harinarayan, N.H. and A. Kumar (2017 b). Seismic Site Classification of Recording Stations in Tarai Region of Uttarakhand, from Multiple Approaches, Geotech. Geol. Eng., 36(3), 1-16.

Harinarayan, N.H. and A. Kumar (2018). Determination of NEHRP Site Class of Seismic Recording Stations in the Northwest Himalayas and Its Adjoining Area Using HVSR Method, Pure Appl. Geophys., 175(1), 89-107.

Hartzell, S.H. (1992). Site response estimation from earthquake data, Bull. Seismol. Soc. Am., 82(6), 2308-2327.

Hassani, B., H. Zafarani, J. Farjoodi and A. Ansari (2011). Estimation of site amplification, attenuation and source spectra of S-waves in the East-Central Iran, Soil Dyn. Earthquake Eng., 31(10), 1397-1413.

IS 1893: Part 1-2016. Indian standard criteria for earthquake resistant design of structures - part 1, General Provisions and Buildings, Bureau of Indian Standards, New Delhi, India.

Iwata, T., and K. Irikura (1998). Source parameters of the 1983 Japan Sea earthquake sequence, J. of Physics of the Earth, 36(4), 155-184.

Joshi, A., M. Mohanty, A.R. Bansal, V.P. Dimri, R.K. Chadha (2010). Use of spectral acceleration data for determination of three-dimensional attenuation structure in the Pithoragarh region of Kumaon Himalaya, J. Seismol., 14(2), 247-272.

Joshi, A., (2006). Use of acceleration spectra for determining the frequency-dependent attenuation coefficient and source parameters, Bull. Seismol. Soc. Am., 96(6), 2165-2180.

Kamp, U., B.J. Growley, G.A. Khattak, and L.A. Owen, (2008). GIS-based landslide susceptibility mapping for the 2005 Kashmir earthquake region, Geomorphology, 101(4), 631-642.

Kim, K.D., T.W. Chung and J.B. Kyung (2004). Attenuation of high-frequency P and S waves in the crust of Choongchung provinces, central South Korea, Bull. Seismol. Soc. Am., 94(3), 1070-1078.

Konno, K. and T. Ohmachi (1998). Ground-motion characteristics estimated from spectral ratio between horizontal 
and vertical components of microtremor, Bull. Seismol. Soc. Am., 88(1), 228-241.

Kumar, A., H. Mittal, R. Sachdeva and A. Kumar (2012). Indian strong motion instrumentation network, Seismol. Res. Lett., 83(1), 59-66.

Kumar, N., J. Sharma, B.R. Arora and S. Mukhopadhyay (2009). Seismotectonic model of the Kangra-Chamba sector of northwest Himalaya: Constraints from joint hypocenter determination and focal mechanism, Bull. Seismol. Soc. Am., 99(1), 95-109.

Kumar, K.V., T.R. Martha and P.S. Roy (2006). Mapping damage in the Jammu and Kashmir caused by 8 October 2005 Mw 7.3 earthquake from the Cartosat-1 and Resourcesat-1 imagery, Int. J. of Remote Sensing 27(20), 44494459.

Kayal, J.R., (1996). Precursor seismicity, foreshocks and aftershocks of the Uttarkashi earthquake of October 20, 1991 at Garhwal Himalaya, Tectonophysics, 263(1-4), 339-345.

Kvamme, L.B., J. Havskov (1995). Q in southern Norway, Bull. Seismol. Soc. Am., 79(5), 1575-1588, 1989.

Lay, T., T.C. Wallace (1995). Modern global seismology, (58) Elsevier, 521.

Lermo, J. and F.J. Chávez-García (1993). Site effect evaluation using spectral ratios with only one station, Bull. Seismol. Soc. Am., 83(5), 1574-1594.

Luzi, L., R., Puglia, F., Pacor, M.R. Gallipoli, D. Bindi and M. Mucciarelli (2011). Proposal for a soil classification based on parameters alternative or complementary to $V_{s 30}$, Bull. Seismol. Soc. Am., 9(6),1877-1898.

Ma'hood, M., H. Hamzehloo, G.J. Doloei (2009). Attenuation of high frequency P and S waves in the crust of the East-Central Iran, Geophys. J. Int., 179(3), 1669-1678.

Mahajan, A.K., and S.K. Kumar (2004). Macroseismic field observations of January 26th, 2001 Kachchh earthquake and its seismotectonics, J. Asian Earth Sci., 23, 17-23.

Menke, W. (2012). Geophysical data analysis: discrete inverse theory: MATLAB edition (Vol. 45). Academic press.

Mukhopadhyay. S., J.R. Kayal (2003). Seismic tomography structure of the 1999 Chamoli earthquake source area in the Garhwal Himalaya, Bull. Seismol. Soc. Am., 93(4), 1854-1861.

Mukhopadhyay, S., J. Sharma, E. Del Pezzo, and N. Kumar (2010). Study of attenuation mechanism for GarwhalKumaun Himalayas from analysis of coda of local earthquakes, Phys. Earth Planet Inter., 180(1-2), 7-15.

Mukhopadhyay, S., A. Kumar, A. Garg, E. Del Pezzo and J.R. Kayal (2014). The attenuation mechanism of S-waves in the source zone of the 1999 Chamoli earthquake, J. of Asian Earth Sciences, 79, 446-454.

Nakamura, Y. (1989). A method for dynamic characteristics estimation of subsurface using microtremor on the ground surface, Railway Technical Research Institute, Quarterly Reports, 30(1).

Nath, S.K., P. Sengupta and J.R. Kayal (2002). Determination of S-wave site response in the Garhwal Himalaya from the aftershock sequence of the 1999 Chamoli earthquake, Bull. Seismol. Soc. Am., 92(3), 1072-1081.

Negi, S.S., A. Paul and A. Joshi (2015). Body wave crustal attenuation characteristics in the Garhwal Himalaya, India, Pure Appl. Geophys., 172(6), 1451-1469.

Oth, A., D. Bindi, S. Parolai, D. Di Giacomo (2011). Spectral Analysis of K-NET and KiK-net Data in Japan, Part II: On Attenuation Characteristics, Source Spectra, and Site Response of Borehole and Surface Stations Spectral Analysis of K-NET and KiK-net Data in Japan, Part II., Bull. Seismol. Soc. Am., 101(2), 667-687.

Oth, A., D. Bindi, S. Parolai and F. Wenzel (2008). S-wave attenuation characteristics beneath the Vrancea region in Romania: new insights from the inversion of ground-motion spectra, Bull. Seismol. Soc. Am., 98(5), 24822497.

Oth, A., S. Parolai, D. Bindi and F. Wenzel (2009). Source spectra and site response from S waves of intermediatedepth Vrancea, Romania, earthquake, Bull. Seismol. Soc. Am., 99(1), 235-254.

Pandey, B., R.S. Jakka and A. Kumar (2016a). Influence of local site conditions on strong ground motion characteristics at Tarai region of Uttarakhand, India. Nat. Hazards, 81(2), 1073-1089.

Pandey, B., R.S. Jakka, A. Kumar and H. Mittal (2016 b). Site Characterization of Strong-Motion Recording Stations of Delhi Using Joint Inversion of Phase Velocity Dispersion and H/V Curve, Bull. Seismol. Soc. Am., 106(3), 1254-1266.

Parolai, S., D. Bindi, M. Baumbach, H. Grosser, C. Milkereit, S. Karakisa and S. Zünbül (2004). Comparison of different site response estimation techniques using aftershocks of the 1999 Izmit earthquake, Bull. Seismol. Soc. Am., 94(3), 1096-1108.

Parvez, I.A., P. Yadav, K. Nagaraj (2012). Attenuation of P, S and coda waves in the NW-Himalayas, India, Int. J. of Geosc., 3(01), 179. 


\section{Nelliparanbil Hareeshkumar Harinarayan and Abhishek Kumar}

Penrose, R. (1955). A Generalized Inverse for Matrices, Proc. Cambridge Phil. Soc., 51, 406-413.

Philip, G., N. Suresh and S.S. Bhakuni (2014). Active tectonics in the northwestern outer Himalaya: evidence of large-magnitude paleoearthquakes in Pinjaur Dun and the Frontal Himalaya, Curr. Sci., 106, 211-222.

Rao, N.P., P. Kumar, T. Tsukuda and D.S. Ramesh (2006). The devastating Muzaffarabad earthquake of 8 October 2005: New insights into Himalayan seismicity and tectonics. Gondwana Research, 9(4), 365-378.

Saikia, S., S. Chopra, S. Baruah, P.R. Baidya, and U.K. Singh (2016). Crustal imaging of the Northwest Himalaya and its foredeep region from teleseismic events, Geomat. Nat. Haz. Risk J., 7(4), 1265-1286.

Sarkar, I., A.K. Pachauri and M. Israil (2011). On the damage caused by the Chamoli earthquake of 29 March, 1999 , J. Asian Earth Sci., 19, 129-134.

Sharma, B., P. Chingtham, A.K. Sutar, S. Chopra and H.P. Shukla (2015). Frequency dependent attenuation of seismic waves for Delhi and surrounding area, India, Ann. Geophys., 58(2), 0216.

Sharma, J., S. Chopra and K.S. Roy (2013). Estimation of source parameters, quality factor (QS), and site characteristics using accelerograms: Uttarakhand Himalaya region, Bull. Seismol. Soc. Am. 104(1), 360-380, 2013.

Shoji, Y. and M. Kamiyama (2002). Estimation of local site effects by a generalized inversion scheme using observed records of “Small-Titan”, Soil Dyn. Earthq. Eng., 22(9), 855-864.

Singh, C., A. Singh, V.S. Bharathi, A.R. Bansal and R.K. Chadha (2012). Frequency-dependent body wave attenuation characteristics in the Kumaun Himalaya, Tectonophysics, 524, 37-42.

Srivastava, H.N., B.K. Bansal and M. Verma (2013). Largest earthquake in Himalaya: An appraisal, J. Geol. Soc. India., $82,15-22$.

Tripathi, J., P. Singh and M.L. Sharma (2014). Attenuation of high-frequency P and S waves in Garhwal Himalaya, India, Tectonophysics, 636, 216-227.

Valdiya, K.S., (1984). Aspects of Tectonics, Focus on south-central Asia, Tata McGraw-Hill Publishing Company Ltd., New Delhi, 319.

Yaghmaei-Sabegh S., (2014). Characteristics of near-source ground motions from the 2012 Varzaghan-Ahar double Earthquakes, Northwest of Iran. Nat. Hazards, 70, 1077-1097.

Yoshimoto, K., H. Sato and M. Ohtake (1993). Frequency-dependent attenuation of P and S waves in the Kanto area, Japan, based on the coda-normalization method, Geophys. J. Int., 114(1), 165-174.

Ren, Y., Y, Zhou, H. Wang and R. Wen (2018). Source Characteristics, Site Effects, and Path Attenuation from Spectral Analysis of Strong-Motion Recordings in the 2016 Kaikōura Earthquake Sequence, Bull. Seismol. Soc. Am., 108(3B), 1757-1773.

Wang, H., Y. Ren and R. Wen (2018). Source parameters, path attenuation and site effects from strong-motion recordings of the Wenchuan aftershocks (2008-2013) using a non-parametric generalized inversion technique, Geophys. J. Int., 212(2), 872-890.

Wang, H., Y. Ren, R. Wen and P. Xu (2019). Breakdown of Earthquake Self-Similar Scaling and Source Rupture Directivity in the 2016-2017 Central Italy Seismic Sequence, J. of Geophys. Res.: Solid Earth, 124(4), 3898-3917. 